\title{
A systematic review of therapeutic outcomes following treatment of squamous cell carcinoma of the retromolar trigone
}

\author{
Hye-Won Kim, Moon-Young Kim, Chul-Hwan Kim \\ Department of Oral and Maxillofacial Surgery, College of Dentistry, Dankook University, Cheonan, Korea
}

\begin{abstract}
J Korean Assoc Oral Maxillofac Surg 2021;47:291-314)
Squamous cell carcinoma (SCC) of the retromolar trigone (RMT) is a rare but potentially fatal disease that carries a poor prognosis due to its unique anatomic position. RMT SCCs tend to spread to vital nearby structures, including the tonsillar pillar, masticatory muscles, and underlying mandibular bone, even in their early stages, and aggressive treatment is often warranted. This systematic review appraises and qualitatively analyzes all available literature regarding the survival outcomes and prognosis of RMT SCC. Four databases were searched to identify all eligible articles published since January 1980. Of the 1,248 studies, a total of 15 studies representing 4,838 cases met the inclusion criteria. The evaluated patients had a high rate of advanced tumor stage (T3 or T4: 61.4\%), lymph node metastasis (38.8\%), and mandibular bone invasion (24\%) at the time of diagnosis. Aggressive surgical treatments such as lip-splitting (92\%), segmental mandibulectomy (61.1\%), radical neck dissection (44.1\%), and reconstruction using free flaps $(49.5 \%$ ) was undertaken for $92 \%$ of the pooled patient population. The mean rates for local, regional, and systemic recurrence were $23.40 \%, 8.40 \%$, and $8.50 \%$, respectively. The mean 5-year overall survival rate was $38.90 \%$. Osteonecrosis was noted in $11.6 \%$ of the 328 patients who received radiotherapy. In conclusion, RMT SCC is generally associated with high recurrence, low survival, and high postoperative complication rates. Early diagnosis and aggressive treatment are thus warranted. However, significant methodological problems hamper current knowledge. Future studies of this topic that use randomized or cohort designs are thus needed.
\end{abstract}

Key words: Oral cancer, Oral cavity, Squamous cell carcinoma, Oral manifestations, Maxillofacial surgery

[paper submitted 2021. 2. 3 / revised 2021. 3. 29 / accepted 2021. 3. 29]

\section{Introduction}

The retromolar trigone (RMT) area is a posterior triangular mucosal region in the oral cavity overlying the ascending ramus and extending from the third molar to its apex at the maxillary tuberosity ${ }^{1}$. Squamous cell carcinoma (SCC) of the RMT is a rare entity, accounting for $3.7 \%$ to $9.1 \%$ of all SCCs that arise primarily in the oral cavity ${ }^{2-4}$. However, owing to its unique spatial relationship with surrounding vital structures, carcinomas of this subsite are associated with an aggressive clinical course and consequent poor prognosis that differs drastically from that of similar cancers in nearby oral

\section{Chul-Hwan Kim}

Department of Oral and Maxillofacial Surgery, College of Dentistry, Dankook University, 119 Dandae-ro, Cheonan 31116, Korea

TEL: +82-41-550-1996

E-mail:kimchoms@gmail.com

ORCID: https://orcid.org/0000-0002-5199-2420

(c) This is an open-access article distributed under the terms of the Creative Commons Attribution Non-Commercial License (http://creativecommons.org/ licenses/by-nc/4.0/), which permits unrestricted non-commercial use, distribution, and reproduction in any medium, provided the original work is properly cited.

Copyright (C) 2021 The Korean Association of Oral and Maxillofacial Surgeons. regions $^{5}$.

Given its rare presentation, existing evidence regarding the treatment and prognosis of RMT SCC is scarce and has been documented only through case reports and small case series. Consequently, establishing adequate treatment guidelines according to the anticipated effects of tumors arising from this sublocation has been a difficult endeavor. The aim of this article is to provide a qualitative assessment of the outcomes and potential prognostic factors of RMT SCC through a systematic evaluation of the current literature.

The following PICOS (Patient population, Intervention, Comparatic controls, Outcomes, Statistical analysis) question $^{6}$ was established to address the objective of this study: "In patients with biopsy-proven SCC of the RMT, which patient-, tumor-, and therapy-related variables can influence the outcomes and complications following treatment when compared one to the other, as demonstrated by randomized or non-randomized clinical trials and cohort and case-control studies?" 


\section{Materials and Methods}

\section{Literature search}

This systematic review was performed in accordance with the recommended 'Preferred Reporting Items for Systematic Reviews and Meta-Analyses (PRISMA) Guidelines" ${ }^{7}$. An adequate search strategy for each database was designed with the support of a trained librarian. Preliminary trials were performed to identify the best search terms.

\section{Study inclusion and exclusion criteria}

The following inclusion criteria were designed a priori to select eligible studies for the systematic review. (1) Study design: All randomized, controlled clinical trials and cohort, case-control, and case series studies investigating the outcomes of various treatment modalities for RMT SCC and published in the English language were included. (2) Target patient population: All patients who underwent treatment for biopsy-proven RMT SCC and had pathological staging information available were included. (3) Interventions: Studies that used one or more of the following treatment modalities - surgical resection, radiotherapy, chemotherapy - were considered. (4) Outcome: Studies that evaluated the survival rates, complications, recurrences, or functional outcomes following treatment were considered.

Studies were excluded if they were published before 1980, if more than $50 \%$ of the subjects had SCC with its epicenter in regions other than the RMT, or if fewer than 10 cases were included in the final analysis. Case reports and grey literature such as abstracts, conference presentations, editorials, and expert opinions were excluded to limit the possibility of duplicated results.

Furthermore, among the duplicate studies with accumulating numbers of patients or increased lengths of follow-up that were published by the same institution, only the most complete reports were selected for analysis.

\section{Search strategy}

Electronic database searches were performed of the Cochrane Library, Embase, PubMed, and ScienceDirect. To ensure that the included studies were up-to-date, the search was limited to research published after January 1980. To achieve maximum sensitivity in the search and thus identify all relevant articles, we combined the following terms as keywords:
("Retromolar Trigone") AND ("Cancer" OR "Carcinoma") AND ("Outcome" OR "Prognosis" OR "Survival"). To identify other potentially relevant articles, we also conducted a manual review of the references in all the retrieved articles.

\section{Study selection}

For screening and data management, the retrieved citation abstracts and full text articles were uploaded to Distiller Systematic Review (DSR) software, an internet-based software program that facilitates collaboration among reviewers during the study selection process. Two authors (H.W.K. and M.Y.K.) discussed and developed screening forms and relevant questions based on the inclusion and exclusion criteria to complete the formal screening form in the DSR software.

The screening was performed in two phases. For phase I screening, two authors (H.W.K. and M.Y.K.) independently reviewed the titles, keywords, and abstracts of all references and selected articles with abstracts that met the inclusion criteria. The same authors then independently carried out the second screening phase by reviewing the full texts of the literature selected in phase I. Those that did not meet the inclusion criteria, as selected a priori, were excluded. Discrepancies were resolved through comparison and mutual agreement between the two authors. A third author (C.H.K.) resolved disagreements when the two authors failed to reach consensus.

Table 1. Methodologic score for the studies included

\begin{tabular}{|c|c|c|}
\hline & & Criteria \\
\hline \multicolumn{3}{|c|}{ Study design $(8 \checkmark)$} \\
\hline A & Objective & Clearly defined $(\checkmark)$ \\
\hline B & Population & Clearly described $(\checkmark)$ \\
\hline $\mathrm{C}$ & Sample size & Considered adequate $(\checkmark)$ \\
\hline & Selection criteria & Clearly described $(\checkmark)$ \\
\hline $\mathrm{E}$ & Follow-up length & Clearly described $(\checkmark)$ \\
\hline $\mathrm{F}$ & Type of study & $\operatorname{RCT}(\checkmark \checkmark \checkmark), \operatorname{CT}(\checkmark \checkmark), \operatorname{CS}(\checkmark)$ \\
\hline \multicolumn{3}{|c|}{ Study measurements $(4 \checkmark)$} \\
\hline G & Measurement method & Mentioned $(\checkmark)$, appropriate $(\checkmark)$ \\
\hline $\mathrm{H}$ & $\begin{array}{l}\text { Reliability for measuring } \\
\text { survival }\end{array}$ & $\begin{array}{l}\text { Overall survival described } \\
(\checkmark), 5 \text {-year overall survival } \\
\text { described }(\checkmark)\end{array}$ \\
\hline \multicolumn{3}{|c|}{ Statistical analysis $(4 \sqrt{ })$} \\
\hline & Dropouts & Accounted $(\checkmark)$ \\
\hline $\mathrm{J}$ & Statistical analysis & Appropriate $(\checkmark)$ \\
\hline $\mathrm{K}$ & Presentation of data & $\begin{array}{l}\text { Exact } P \text {-value stated }(\checkmark) \text {, } \\
\text { variability measures (SD or CI) } \\
\text { stated }(\checkmark)\end{array}$ \\
\hline
\end{tabular}

(RCT: randomized controlled trial, CT: cohort study, CS: case series, SD: standard deviation, CI: confidence interval)

Hye-Won Kim et al: A systematic review of therapeutic outcomes following treatment of squamous cell carcinoma of the retromolar trigone. J Korean Assoc Oral Maxillofac Surg 2021 


\section{Risk of bias assessment}

Before the assessment, the three reviewers analyzed and discussed adequate tools for evaluating the quality of the selected studies. A modified version of the method suggested by Saltaji et al. ${ }^{8}$ was chosen to assess the risk of bias in individual articles.(Table 1) The symbol ' $\checkmark$ ' and a score of 1 was given for every question answered as 'yes.' The answer 'no' was indicated by the symbol ' $x$ ' and did not contribute to the total score. The score that could be attributed to each study ranged from 0 to 16 , and final risk of bias was classified as follows: low risk of bias if the score was 16 ; moderate risk of bias if the score was $\geq 10$ and $<16$; high risk of bias if the score was $<10$. For the assessment, two reviewers (H.W.K. and M.Y.K.) independently assessed all of the included studies and then compared their results. Unresolved disagreements between the two reviewers were resolved by the third reviewer (C.H.K.).

\section{Data management and extraction}

A data extraction form was developed a priori via the DSR data management program. Using this worksheet, the data screening and extraction were conducted in duplicate by two independent reviewers (H.W.K. and M.Y.K.). Calibration exercises were conducted before the data extraction process to ensure consistency between the reviewers. Discrepancies were resolved through comparison and mutual agreement between the two authors, with a third author (C.H.K.) resolving disagreements when the two authors failed to reach consensus. The third reviewer (C.H.K.) also checked the final extracted data for accuracy and completeness. The data extracted were the study design, aim, location, and mean follow-up period; patient (age, sex, comorbidities) and tumor (sublocation, stage, nodal status, bone invasion) characteristics; treatment modalities; outcome measurement tools; and results. The retrieved data were synthesized by the DSR program.

\section{Results}

The review stages and details of identification, exclusion, and inclusion following the assessment for eligibility are portrayed in the PRISMA flowchart.(Fig. 1) The searches of the four electronic databases and other sources, such as the reference lists of the included articles, yielded 1,248 articles. After eliminating duplicates, 1,083 unique articles remained. The phase I assessment removed 968 irrelevant citations, leaving 115 full-text articles to be evaluated for eligibility.

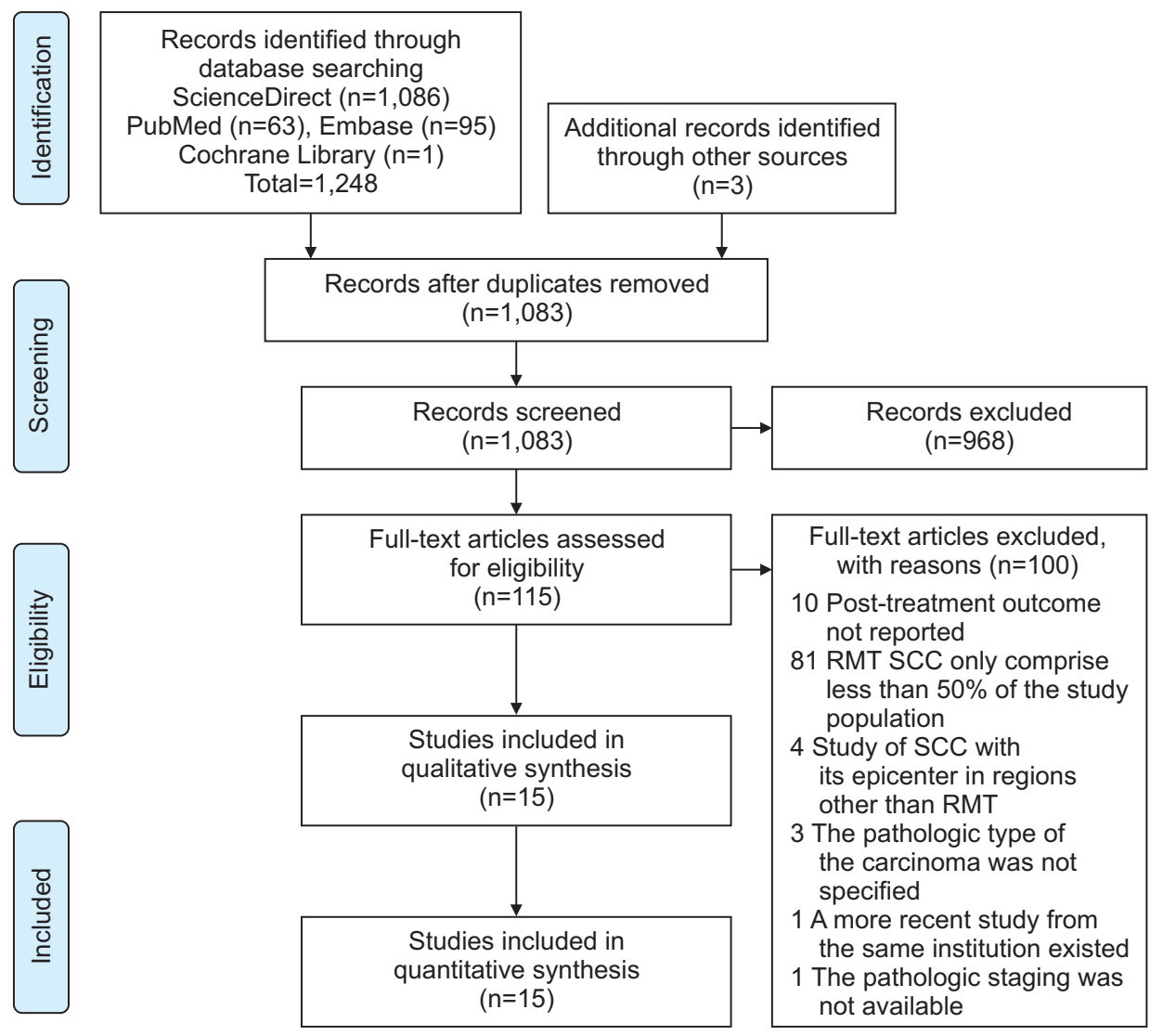

Fig. 1. Preferred Reporting Items for Systematic Reviews and Meta-Analyses (PRISMA) flowchart. (RMT: retromolar trigone, SCC: squamous cell carcinoma)

Hye-Won Kim et al: A systematic review of therapeutic outcomes following treatment of squamous cell carcinoma of the retromolar trigone. J Korean Assoc Oral Maxillofac Surg 2021 
Table 2. Summary of the patient, tumor, and treatment characteristics and prognosis of included subjects

\begin{tabular}{|c|c|c|}
\hline \multicolumn{2}{|c|}{ Variable } & \multirow{2}{*}{$\begin{array}{l}\text { Value } \\
4,838\end{array}$} \\
\hline Sample size (n) & Total & \\
\hline & Average & 323 \\
\hline Follow-up period (mo) & Range & $15-67$ \\
\hline \multirow[t]{4}{*}{ Location $(n=15)$} & North America & 7 \\
\hline & Asia & 4 \\
\hline & Europe & 3 \\
\hline & South America & 1 \\
\hline \multirow[t]{2}{*}{ Mean age (yr) } & Range & $50-67$ \\
\hline & Total average & 63.8 \\
\hline \multirow[t]{2}{*}{ Sex } & Male & 69.70 \\
\hline & Female & 30.30 \\
\hline \multirow[t]{3}{*}{ T stage } & T1-2 & 61.40 \\
\hline & T3-4 & 37.40 \\
\hline & Not reported & 1.20 \\
\hline \multirow{2}{*}{$\begin{array}{l}\text { Pathological nodal } \\
\text { metastasis (among } 12 \\
\text { studies, } n=724 \text { ) }\end{array}$} & Positive & 38.80 \\
\hline & Negative & 62.20 \\
\hline \multirow{2}{*}{$\begin{array}{l}\text { Extranodal extension } \\
\text { (among } 8 \text { studies, } \\
\mathrm{n}=451 \text { ) }\end{array}$} & Present & 11.10 \\
\hline & Not present & 88.90 \\
\hline \multirow{2}{*}{$\begin{array}{l}\text { Pathologically confirmed } \\
\text { mandibular bone } \\
\text { invasion (among } 5 \\
\text { studies, } n=283 \text { ) }\end{array}$} & Positive & 24.00 \\
\hline & Negative & 76.00 \\
\hline \multirow{10}{*}{$\begin{array}{l}\text { Tumor sublocation } \\
\text { (among } 7 \text { studies, } \\
\mathrm{n}=443 \text { ) }\end{array}$} & Tonsillar pillar & 36.30 \\
\hline & Soft palate & 35.90 \\
\hline & Lower gum & 32.70 \\
\hline & Buccal mucosa & 20.80 \\
\hline & Tongue base & 9.90 \\
\hline & Floor of mouth & 5.00 \\
\hline & Upper gum & 4.30 \\
\hline & Mobile tongue & 4.10 \\
\hline & Hard palate & 3.60 \\
\hline & Tonsillar fossa & 1.40 \\
\hline \multirow[t]{5}{*}{ Treatment modality } & $\begin{array}{l}\text { Surgery+ adjuvant } \\
\text { therapy }\end{array}$ & 35.00 \\
\hline & Surgery alone & 32.10 \\
\hline & $\begin{array}{r}\text { RT or CCRT alone } \\
\text { (without surgery) }\end{array}$ & 25.00 \\
\hline & $\begin{array}{l}\text { Neoadjuvant } \\
\text { therapy+surgery }\end{array}$ & 1.10 \\
\hline & Unknown & 6.80 \\
\hline \multirow{2}{*}{$\begin{array}{l}\text { Surgical approach } \\
\text { (among } 6 \text { studies, } \\
\mathrm{n}=287 \text { ) }\end{array}$} & $\begin{array}{l}\text { Transoral (without } \\
\text { lip-split) }\end{array}$ & 8.00 \\
\hline & Lip-split & 92.00 \\
\hline \multirow{5}{*}{$\begin{array}{l}\text { Type of mandibulectomy } \\
\text { (among } 9 \text { studies, } \mathrm{n}= \\
396 \text { ) }\end{array}$} & None & 16.40 \\
\hline & Mandibulotomy & 9.10 \\
\hline & $\begin{array}{l}\text { Marginal } \\
\text { mandibulectomy }\end{array}$ & 13.40 \\
\hline & $\begin{array}{l}\text { Segmental } \\
\text { mandibulectomy }\end{array}$ & 21.50 \\
\hline & Hemimandibulectomy & 39.60 \\
\hline Reconstruction (among & Primary closure & 31.90 \\
\hline \multirow{8}{*}{8 studies, $\mathrm{n}=382$ ) } & PMMC & 16.00 \\
\hline & ALT & 13.10 \\
\hline & STSG & 12.30 \\
\hline & Rectus abdominis & 5.00 \\
\hline & FFF & 3.40 \\
\hline & RFFF & 2.10 \\
\hline & Other & 9.90 \\
\hline & Not mentioned & 6.30 \\
\hline
\end{tabular}

Table 2. Continued

\begin{tabular}{|c|c|c|}
\hline \multicolumn{2}{|c|}{ Variable } & \multirow{2}{*}{$\begin{array}{r}\text { Value } \\
5.50\end{array}$} \\
\hline Neck dissection (among & None & \\
\hline 7 studies, $n=347$ ) & I-IV & 7.20 \\
\hline & I-III & 19.60 \\
\hline & mRND & 23.60 \\
\hline & RND & 44.10 \\
\hline \multirow{4}{*}{$\begin{array}{l}\text { Recurrence (among } 13 \\
\text { studies, } \mathrm{n}=770 \text { ) }\end{array}$} & Local recurrence & 23.40 \\
\hline & Regional recurrence & 8.40 \\
\hline & $\begin{array}{l}\text { Locoregional recurrence } \\
\text { (not specified) }\end{array}$ & 5.70 \\
\hline & $\begin{array}{l}\text { Systemic recurrence } \\
\text { (among } 12 \text { studies, } \\
\mathrm{n}=660 \text { ) }\end{array}$ & 8.50 \\
\hline \multirow{2}{*}{$\begin{array}{l}\text { 5-year overall survival } \\
\text { (among } 9 \text { studies, } \\
\mathrm{n}=4,633 \text { ) }\end{array}$} & Range & $26-60.6$ \\
\hline & Total overall survival & 38.90 \\
\hline \multirow{10}{*}{$\begin{array}{l}\text { Postoperative } \\
\text { complications (among } \\
5 \text { studies, } n=395 \text { ) }\end{array}$} & Oro-cutaneous fistula & 10.60 \\
\hline & Flap dehiscence & 8.10 \\
\hline & Wound infection & 8.10 \\
\hline & Flap necrosis & 5.60 \\
\hline & Seroma formation & 3.50 \\
\hline & Pneumonia & 3.50 \\
\hline & PEG tube placement & 2.50 \\
\hline & Hematoma & 1.00 \\
\hline & Mandibular fracture & 0.80 \\
\hline & Carotid rupture & 0.50 \\
\hline $\begin{array}{l}\text { Osteoradionecrosis } \\
\text { (among } 5 \text { studies, } \\
\mathrm{n}=328 \text { ) }\end{array}$ & & 11.60 \\
\hline
\end{tabular}

(RT: radiotherapy, CCRT: concurrent chemoradiotherapy, PMMC: pectoralis major myocutaneous flap, ALT: anterolateral thigh flap, STSG: split thickness skin graft, FFF: fibula free flap, RFFF: radial forearm free flap, mRND: modified radical neck dissection, RND: radical neck dissection, PEG: percutaneous endoscopic gastrotomy) Values are presented as number only, range, or $\%$.

Hye-Won Kim et al: A systematic review of therapeutic outcomes following treatment of squamous cell carcinoma of the retromolar trigone. J Korean Assoc Oral Maxillofac Surg 2021

That process eliminated another 100 articles. Thus, at the end of the selection process, 15 studies remained for the final assessment ${ }^{1,9-22}$. All 15 articles were retrospective case-control studies. A total of 4,838 patients were included in the review. A summary of the overall data for all the included articles is shown in Table 2.

\section{Eligibility and quality assessment}

In the risk of bias assessment, most studies had a total score between 10 and 15 and were thus categorized as having a moderate risk of bias ${ }^{1,9-14,16-18,20-22}$. Two studies presented a score of 9 and were thus classified as having a high risk of bias $^{15,19}$. All the analyzed studies clearly declared their study aim and population. The data measurement methods, which were also stated in all articles, were a retrospective review of medical records in all but one study, which used the nationwide Surveillance, Epidemiology, and End Results (SEER) 
Table 3. Risk of bias scores for the included studies

\begin{tabular}{|c|c|c|c|c|c|c|c|c|c|c|c|c|c|}
\hline \multirow[t]{2}{*}{ Study } & \multicolumn{6}{|c|}{ Study design $(8 \checkmark)$} & \multicolumn{2}{|c|}{$\begin{array}{c}\text { Study } \\
\text { measurements } \\
(4 \sqrt{ })\end{array}$} & \multicolumn{3}{|c|}{$\begin{array}{c}\text { Statistical } \\
\text { analysis }(4 \sqrt{ })\end{array}$} & \multirow[t]{2}{*}{ Total } & \multirow[t]{2}{*}{ Risk of bias } \\
\hline & A & $\mathrm{B}$ & $\mathrm{C}$ & $\mathrm{D}$ & $\mathrm{E}$ & $\mathrm{F}$ & G & $\mathrm{H}$ & I & $\mathrm{J}$ & $\mathrm{K}$ & & \\
\hline Deo et al. ${ }^{9}$ (2013) & $\checkmark$ & $\checkmark$ & $\checkmark$ & $\checkmark$ & $\checkmark$ & $\sqrt{ } \times x$ & $\sqrt{ } \checkmark$ & $\sqrt{ } \times$ & $\checkmark$ & $\checkmark$ & $\sqrt{ } \times$ & 12 & Moderate \\
\hline Huang et al. ${ }^{10}(2001)$ & $\checkmark$ & $\checkmark$ & $\checkmark$ & $\checkmark$ & $x$ & $\sqrt{ } \times x$ & $\sqrt{ } \checkmark$ & $x x$ & $\checkmark$ & $\checkmark$ & $\sqrt{ } \times$ & 10 & Moderate \\
\hline Kowalski et al. ${ }^{11}$ (1993) & $\checkmark$ & $\checkmark$ & $\checkmark$ & $\checkmark$ & $\checkmark$ & $\sqrt{ } \times x$ & $\checkmark \checkmark$ & $\checkmark \checkmark$ & $x$ & $\checkmark$ & $\checkmark \checkmark$ & 13 & Moderate \\
\hline Petruzzelli et al. ${ }_{2}^{13}$ (2003) & $\checkmark$ & $\checkmark$ & $\checkmark$ & $\checkmark$ & $\checkmark$ & $\sqrt{ } \times x$ & $\checkmark \sqrt{ }$ & $x x$ & $\checkmark$ & $\checkmark$ & $\sqrt{ } x$ & 11 & Moderate \\
\hline Binahmed et al. ${ }^{12}$ (2007) & $\checkmark$ & $\checkmark$ & $\checkmark$ & $\checkmark$ & $\checkmark$ & $\sqrt{ } \times x$ & $\checkmark \checkmark$ & $\checkmark \checkmark$ & $\checkmark$ & $\checkmark$ & $\sqrt{ } \times$ & 13 & Moderate \\
\hline Bayman et al. ${ }^{14}$ (2010) & $\checkmark$ & $\checkmark$ & $\checkmark$ & $\checkmark$ & $\checkmark$ & $\sqrt{ } \times x$ & $\sqrt{ } \sqrt{ }$ & $\checkmark \sqrt{ }$ & $x$ & $\checkmark$ & $\checkmark \sqrt{ }$ & 13 & Moderate \\
\hline Factor et al. ${ }^{15}(2020)$ & $\checkmark$ & $\checkmark$ & $x$ & $\checkmark$ & $x$ & $\sqrt{ } \times x$ & $\checkmark \checkmark$ & $x x$ & $x$ & $\checkmark$ & $\checkmark \sqrt{ }$ & 9 & Low \\
\hline Ayad et al. ${ }^{16}(2005)$ & $\checkmark$ & $\checkmark$ & $\checkmark$ & $\checkmark$ & $\checkmark$ & $\sqrt{ } \times x$ & $\checkmark \checkmark$ & $\sqrt{ } \sqrt{ }$ & $\checkmark$ & $\checkmark$ & $\sqrt{ } \times$ & 13 & Moderate \\
\hline Hitchcock et al. ${ }^{17}$ (2015) & $\checkmark$ & $\checkmark$ & $\checkmark$ & $\checkmark$ & $\checkmark$ & $\sqrt{ } \times x$ & $\checkmark \checkmark$ & $\checkmark \checkmark$ & $x$ & $\checkmark$ & $\sqrt{ } \times$ & 12 & Moderate \\
\hline Nishi et al. ${ }^{18}(2018)$ & $\checkmark$ & $\checkmark$ & $\checkmark$ & $x$ & $\checkmark$ & $\sqrt{ } \times x$ & $\checkmark \checkmark$ & $\sqrt{ } \times$ & $x$ & $\checkmark$ & $\sqrt{ } \times$ & 10 & Moderate \\
\hline Byers et al. ${ }^{19}$ (1984) & $\checkmark$ & $\checkmark$ & $\checkmark$ & $\checkmark$ & $x$ & $\sqrt{ } \times x$ & $\checkmark \checkmark$ & $\checkmark \sqrt{ }$ & $x$ & $x$ & $x x$ & 9 & Low \\
\hline Hao et al. ${ }^{20}(2006)$ & $\checkmark$ & $\checkmark$ & $\checkmark$ & $\checkmark$ & $\checkmark$ & $\sqrt{ } \times x$ & $\sqrt{ }$ & $\sqrt{ }$ & $x$ & $\checkmark$ & $\checkmark \checkmark$ & 13 & Moderate \\
\hline $\begin{array}{l}\text { Demir and Öztürk } \\
\text { Yanaşma }^{21}(2020)\end{array}$ & $\checkmark$ & $\checkmark$ & $\times$ & $\checkmark$ & $\checkmark$ & $\sqrt{ } \times x$ & $\checkmark \checkmark$ & $\sqrt{ } \times$ & $\checkmark$ & $\checkmark$ & $\sqrt{ } \times$ & 11 & Moderate \\
\hline Rizvi et al. $^{22}$ (2018) & $\checkmark$ & $\checkmark$ & $\checkmark$ & $\checkmark$ & $x$ & $\sqrt{ } \times x$ & $\checkmark \checkmark$ & $\checkmark \sqrt{ }$ & $x$ & $\checkmark$ & $\checkmark \checkmark$ & 12 & Moderate \\
\hline Faisal et al. ${ }^{1}$ (2017) & $\checkmark$ & $\checkmark$ & $\checkmark$ & $\checkmark$ & $\checkmark$ & $\sqrt{ } \times x$ & $\checkmark \checkmark$ & $\checkmark \sqrt{ }$ & $x$ & $x$ & $x x$ & 10 & Moderate \\
\hline
\end{tabular}

Hye-Won Kim et al: A systematic review of therapeutic outcomes following treatment of squamous cell carcinoma of the retromolar trigone. J Korean Assoc Oral Maxillofac Surg 2021

database $^{22}$. Two studies included fewer than 20 study subjects with RMT SCC, which was considered inadequate ${ }^{1,17}$. The inclusion criteria were not clearly stated in one study ${ }^{18}$, and four studies did not provide details regarding the followup duration for their subjects ${ }^{10,15,19,22}$. Three studies did not provide any data regarding the overall survival rates of their subjects $^{10,13,15}$, and the 5 -year overall survival rates were not stated in three other articles ${ }^{9,18,21}$. Among the studies, only six mentioned the number of dropouts ${ }^{9,10,12,13,16,21}$. Two studies did not specify their method for statistical analysis ${ }^{1,19}$, and confidence intervals were presented in only five $\mathrm{e}^{11,14,15,20,22}$. The results of the bias assessment are summarized in Table 3 .

\section{Study characteristics}

The 15 retrospective case-control studies included in the final analysis ${ }^{1,9-22}$ had heterogeneous populations for sample size, tumor stage, tumor characteristics, reported comorbidities, and treatment modalities. The detailed objectives and subject characteristics for each study are summarized in Table 4. A total of 4,838 patients underwent treatment for histopathologically confirmed RMT SCC from $1960^{11}$ to $2019^{15,21}$. In total, $69.7 \%$ of the subjects were male, and $30.3 \%$ were female. The sample sizes ranged from $14^{15}$ to $4,022^{22}$ participants, and the mean sample size was 323 . The mean age at presentation for the patients analyzed ranged from $50^{9}$ to $67^{12}$ years and was not declared in the study of Hitchcock et al. ${ }^{17}$. The mean follow-up time was $15^{1}$ to $60^{12}$ months. Seven studies were conducted in North America ${ }^{10,12,13,15,17,19,22}$, four in Asia $^{1,9,18,20}$, three in Europe ${ }^{14,16,21}$, and one in South America ${ }^{11}$.
The outcomes of tumors originating from other regions were observed and compared with the RMT SCC group in two articles ${ }^{13,15}$. Six studies documented the rate of comorbidities among their subjects ${ }^{1,9,10,12,15,19}$. Smoking was the most commonly documented comorbidity, comprising $35.5 \%{ }^{1}$ to $97 \%{ }^{19}$ of the various study populations.

\section{Tumor characteristics}

The sublocations to which the tumor extended were specified in seven studies: anterior tonsillar pillar (36.3\%), soft palate $(35.9 \%)$, lower gingiva $(32.7 \%)$, and buccal mucosa (20.8\%) were the primary sublocations. Other reported subsites were the tongue base $(9.9 \%)$, mandible $(5.4 \%)$, floor of mouth $(5.0 \%)$, upper gingiva (4.3\%), mobile tongue $(4.1 \%)$, hard palate (3.6\%), and tonsillar fossa (1.4\%).(Tables 2, 5)

In all the studies, the tumor stage was classified using the primary tumor $(\mathrm{T})$, regional node $(\mathrm{N})$, and metastasis $(\mathrm{M})$ classification of the American Joint Committee on Cancer Staging. Details of the considered tumor stages are provided in Table 2. Among the patients, the presence of pathologically positive lymph nodes was confirmed in $38.8 \%\left(14.5 \%{ }^{19}\right.$ to $\left.65 \%{ }^{21}\right)$. In three studies in which the patients did not undergo surgical treatment ${ }^{14,16,22}$, only clinical lymph node metastasis (ranging from $30.2 \%{ }^{14}$ to $46 \%{ }^{16}$ ) was described. Eight articles ${ }^{1,10,11,13,15,19-21}$ reported the prevalence of histologically confirmed extranodal extension in $11.10 \%\left(0.9 \%{ }^{11}\right.$ to $\left.43 \%{ }^{15}\right)$ of their study populations. Tumor infiltration to the underlying mandibular bone was confirmed histopathologically in $24 \%\left(14 \%{ }^{19}\right.$ to $\left.47.6 \%{ }^{9}\right)$ of the patients in six studies ${ }^{9,13,18-21}$. 


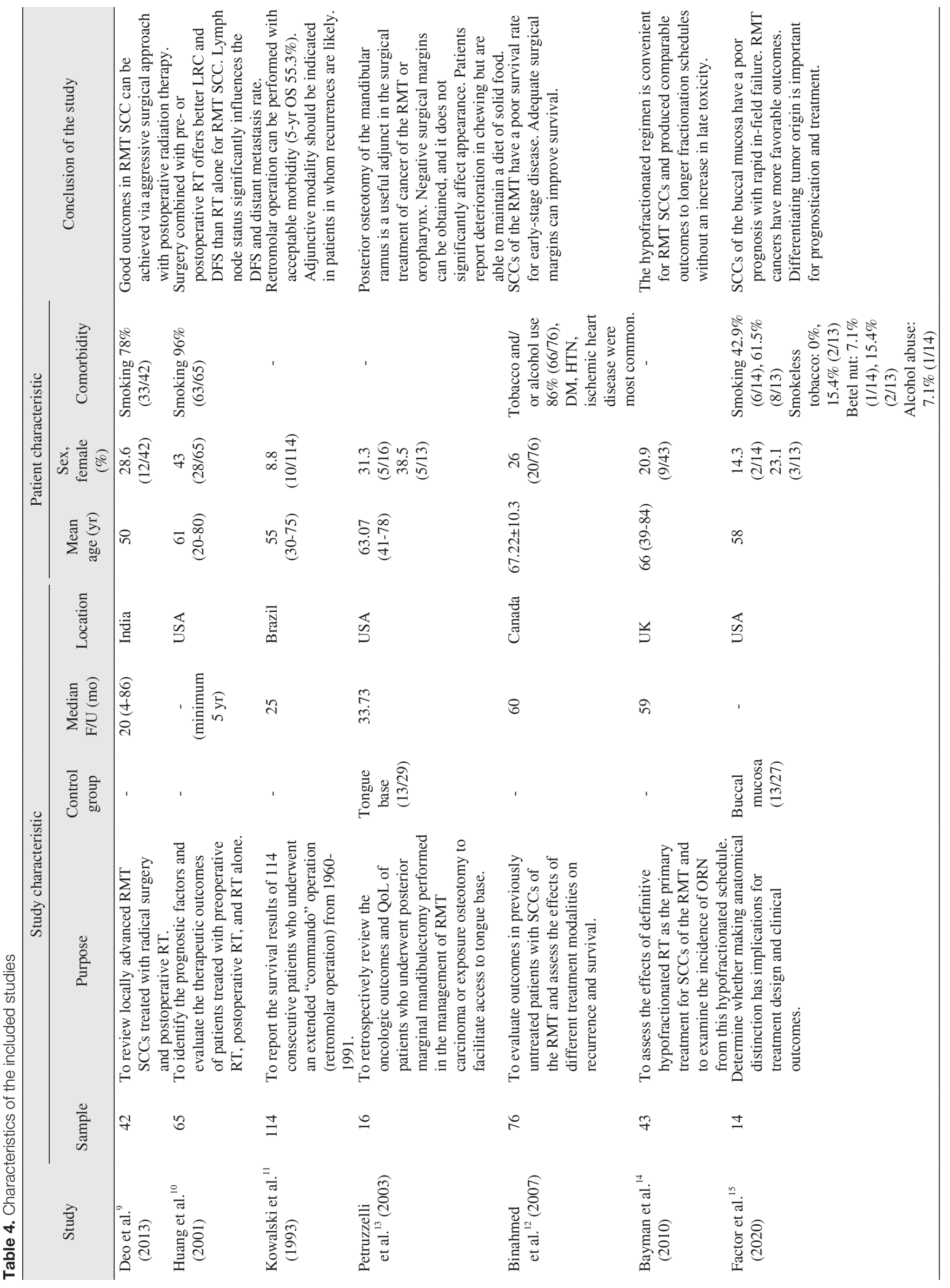




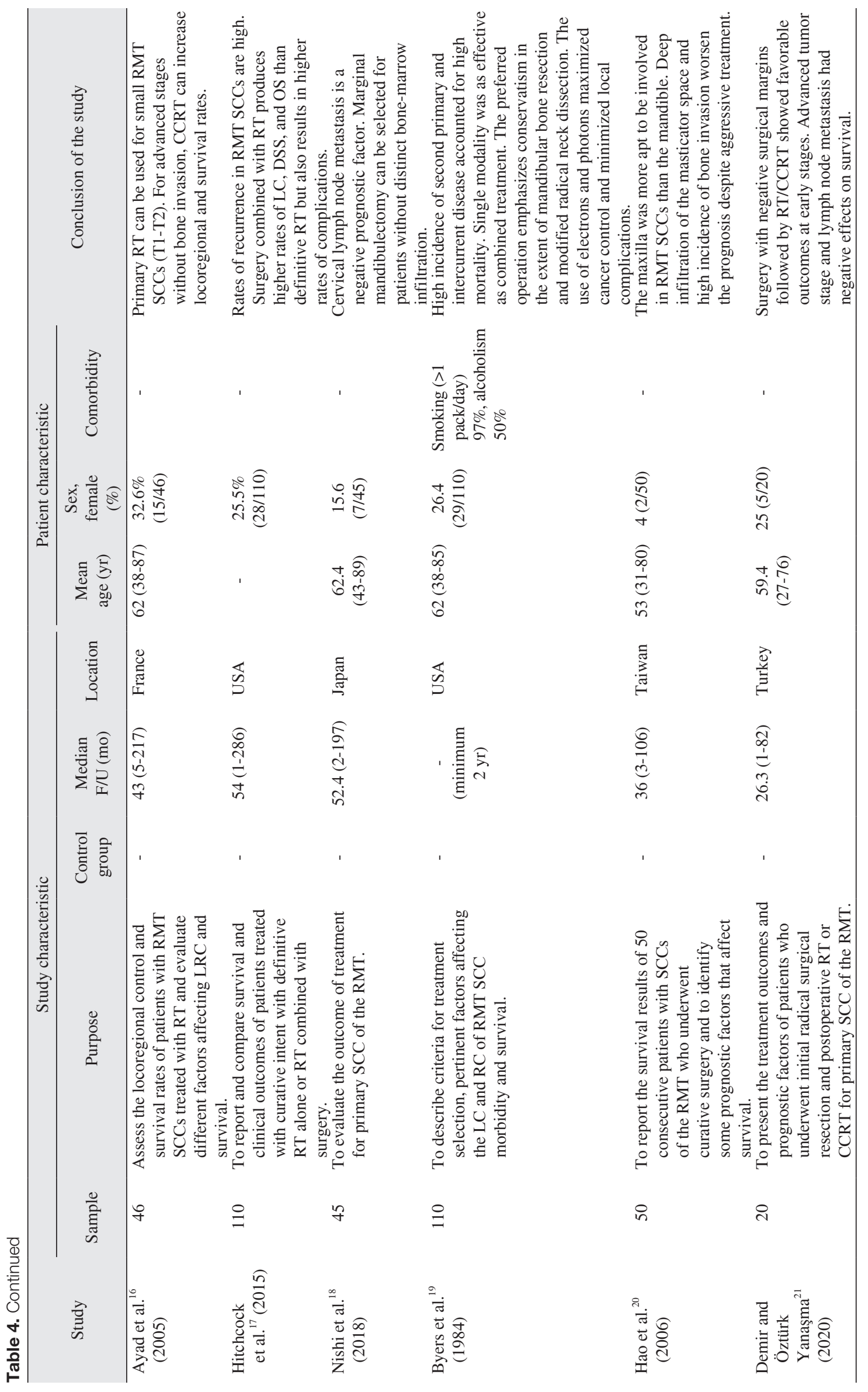




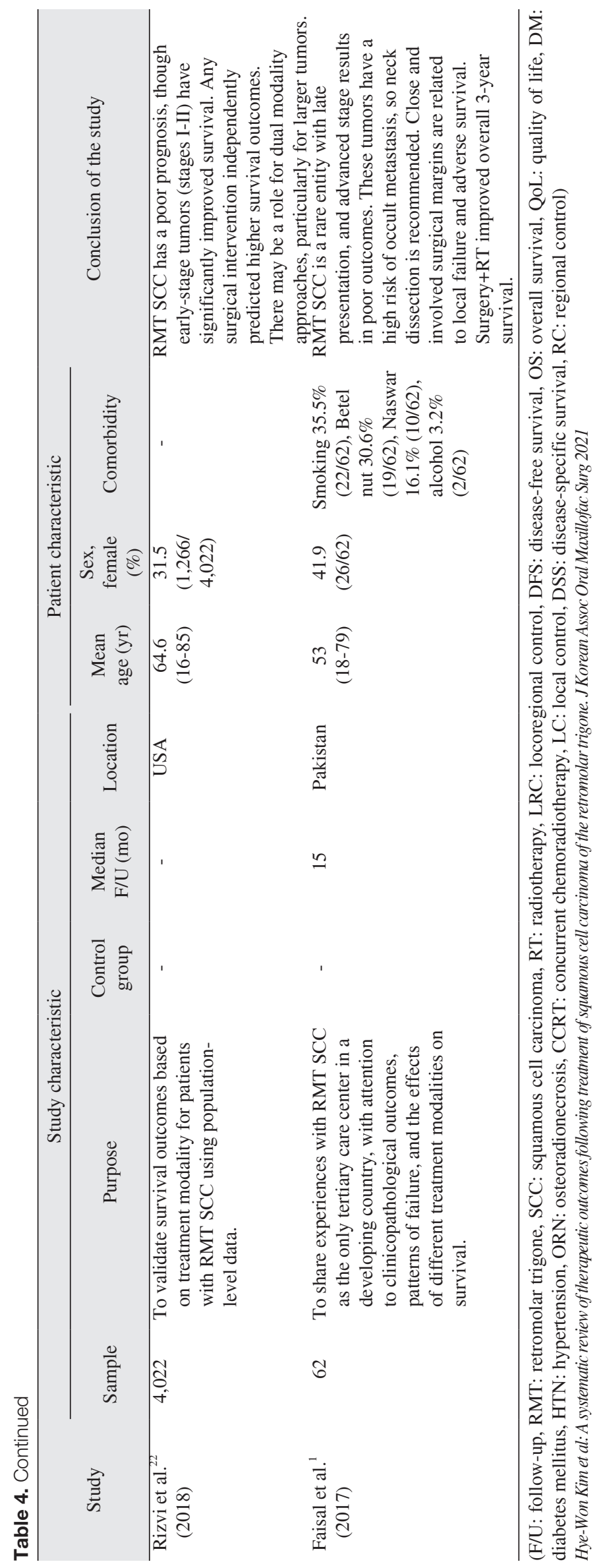




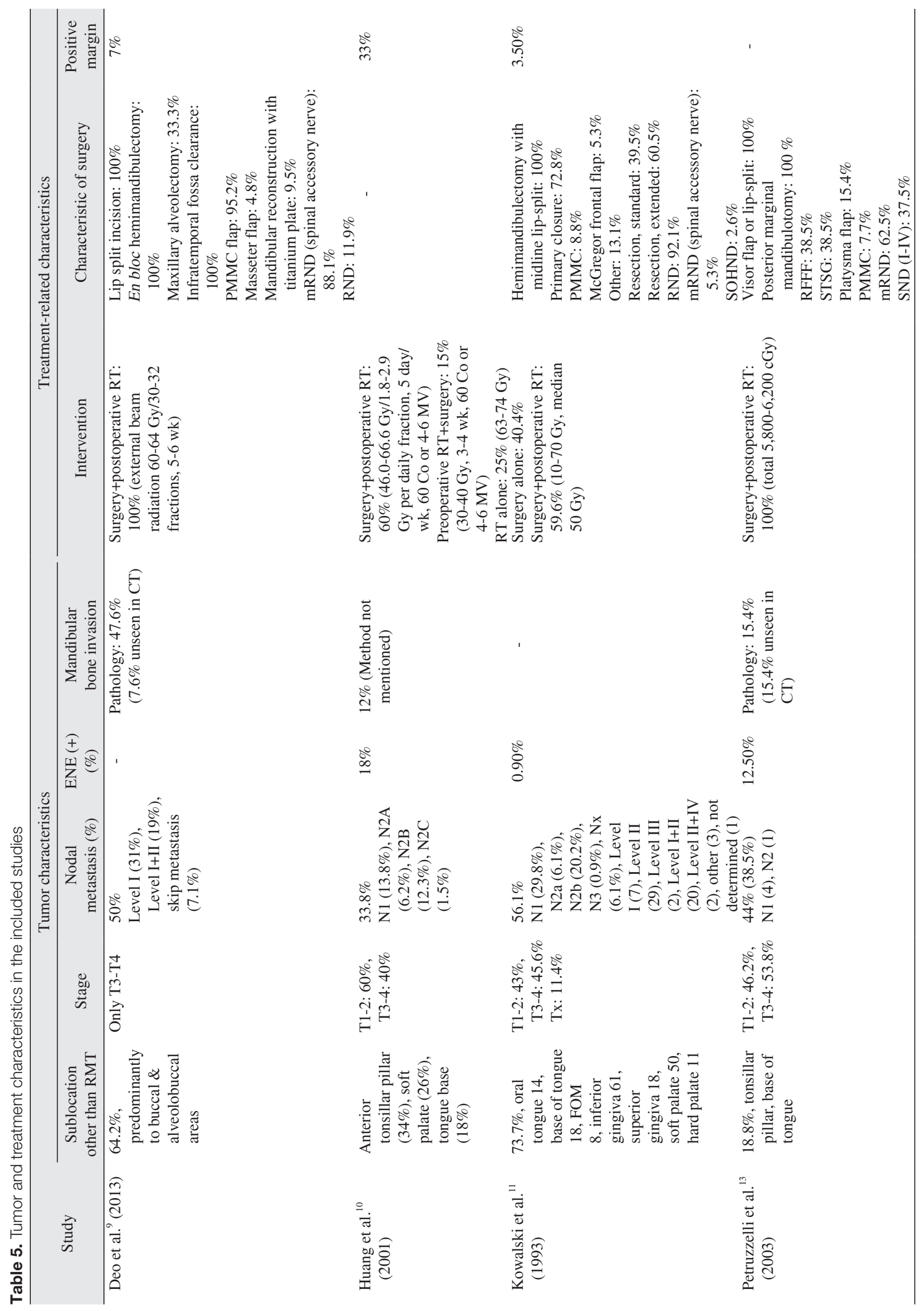




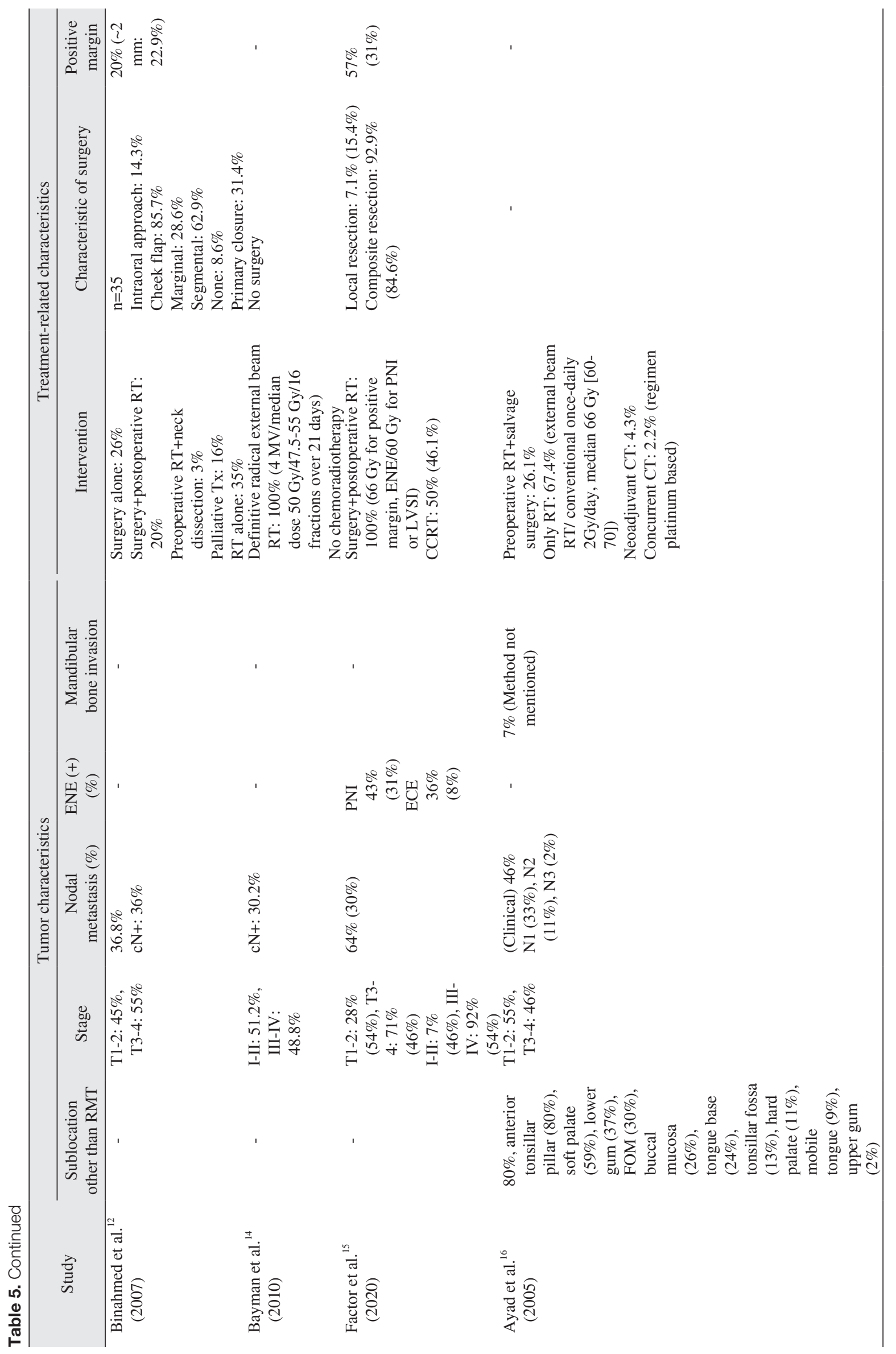




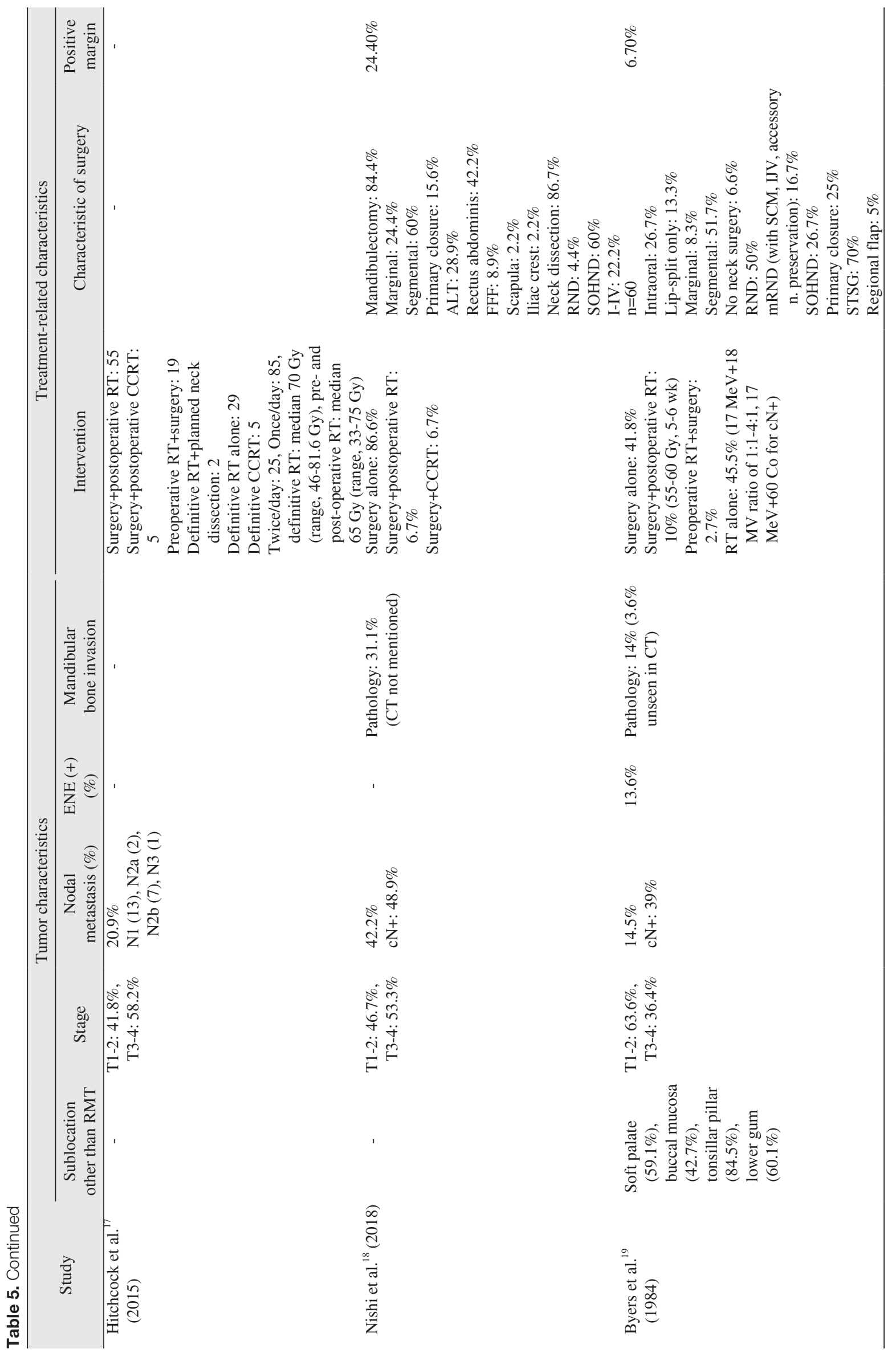




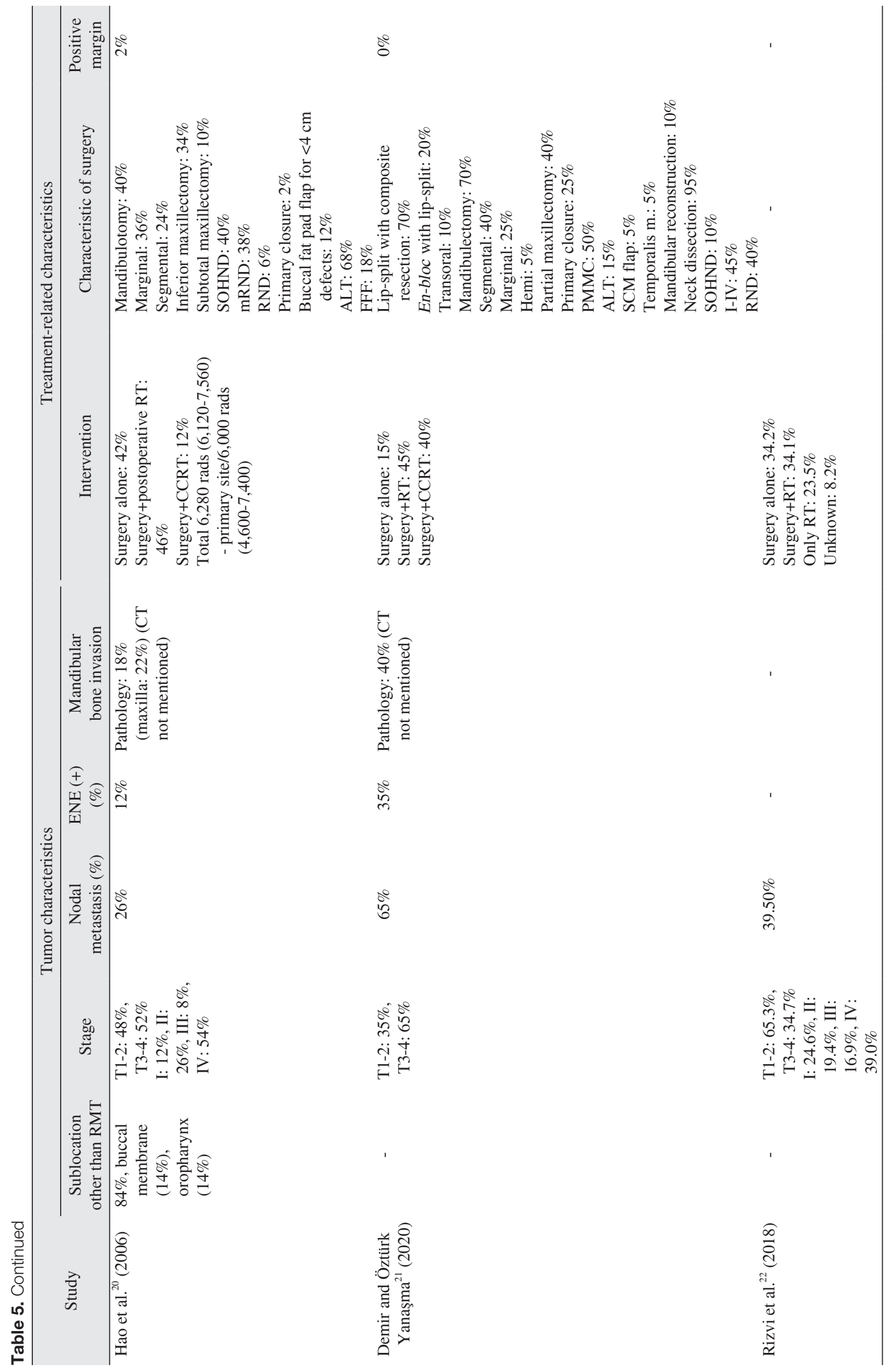




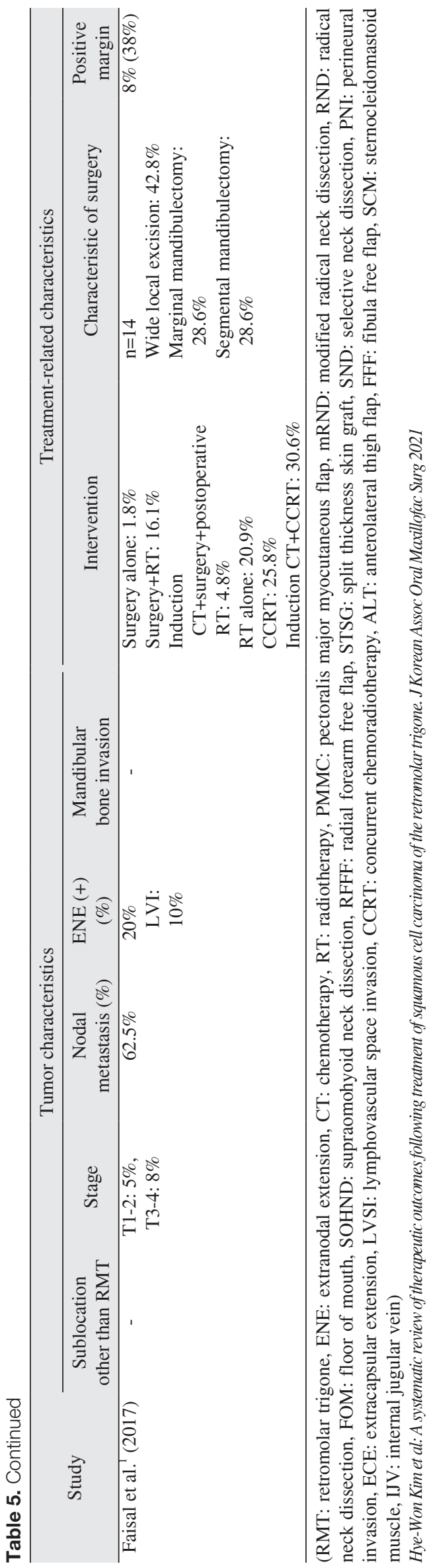

The evaluation method for mandibular infiltration was not specified in two articles ${ }^{10,16}$. Only one study mentioned the invasion rate of the maxilla, 22\% among 50 study subjects, which was higher than that of the mandible ${ }^{20}$.

All the included articles described the treatment modalities performed for patients. Primary surgery followed by adjuvant radiotherapy or chemoradiotherapy was the most commonly used treatment modality, delivered to $35.5 \%$ of the total study population. Differences in treatment methods according to the different $\mathrm{T}$ stage groups were elaborated in only one $\operatorname{article~}^{17}$. According to that study, approximately half of the patients diagnosed with $\mathrm{T}$ stages 1 or 2 and $78.1 \%$ of those with T stage 3 or 4 underwent surgery as the primary modality of treatment. Although the other studies did not clearly specify methods of treatment according to the tumor stages, most mentioned the use of postoperative radiotherapy for patients with pathologically confirmed positive lymph nodes and margins. Among the 8 studies that described the use of chemotherapy ${ }^{1,15-17,20,21}$, only two ${ }^{15,17}$ specified their methods to be platinum based.(Tables 2, 5)

Details regarding surgical procedures and postoperative margin status were provided in ten studies ${ }^{1,9,11-13,15,18-21}$.(Tables 2, 5) Among those patients, $92 \%$ underwent aggressive surgical procedures: lip-splitting (92\%), segmental or hemimandibulectomy (61.1\%), radical neck dissection (44.1\%) or modified radical neck dissection $(23.6 \%)$, and reconstruction via free flaps (49.5\%).(Table 2$)$

\section{Recurrence}

The rate of local and regional recurrence was discussed in all but two studies ${ }^{19,22}$.(Table 6) Among 770 patients, there were 180 cases of local recurrence and 65 cases of regional recurrence. In two studies ${ }^{17,21}$, the type of recurrence was not specified for 44 locoregional recurrence cases. Distant recurrence developed in 56 patients in the 12 studies that discussed distant control following treatment ${ }^{1,9-13,15-18,20,21}$.

Six studies investigated prognostic factors that affected recurrence $e^{10,15-17,19,20}$. Two of them found that primary surgical resection significantly increased local ${ }^{17,19}$ and locoregional control rates ${ }^{10,17}$. In two other studies, advanced tumor stage correlated with significantly decreased regional ${ }^{16}$ and local ${ }^{19}$ control rates. A significant correlation between advanced nodal stage and lower regional control rates was also detected in those studies ${ }^{16,19}$. Nodal metastasis was found to result in higher distant recurrence rates in another study ${ }^{10}$. Hitchcock reported that a higher overall prognostic stage resulted in 


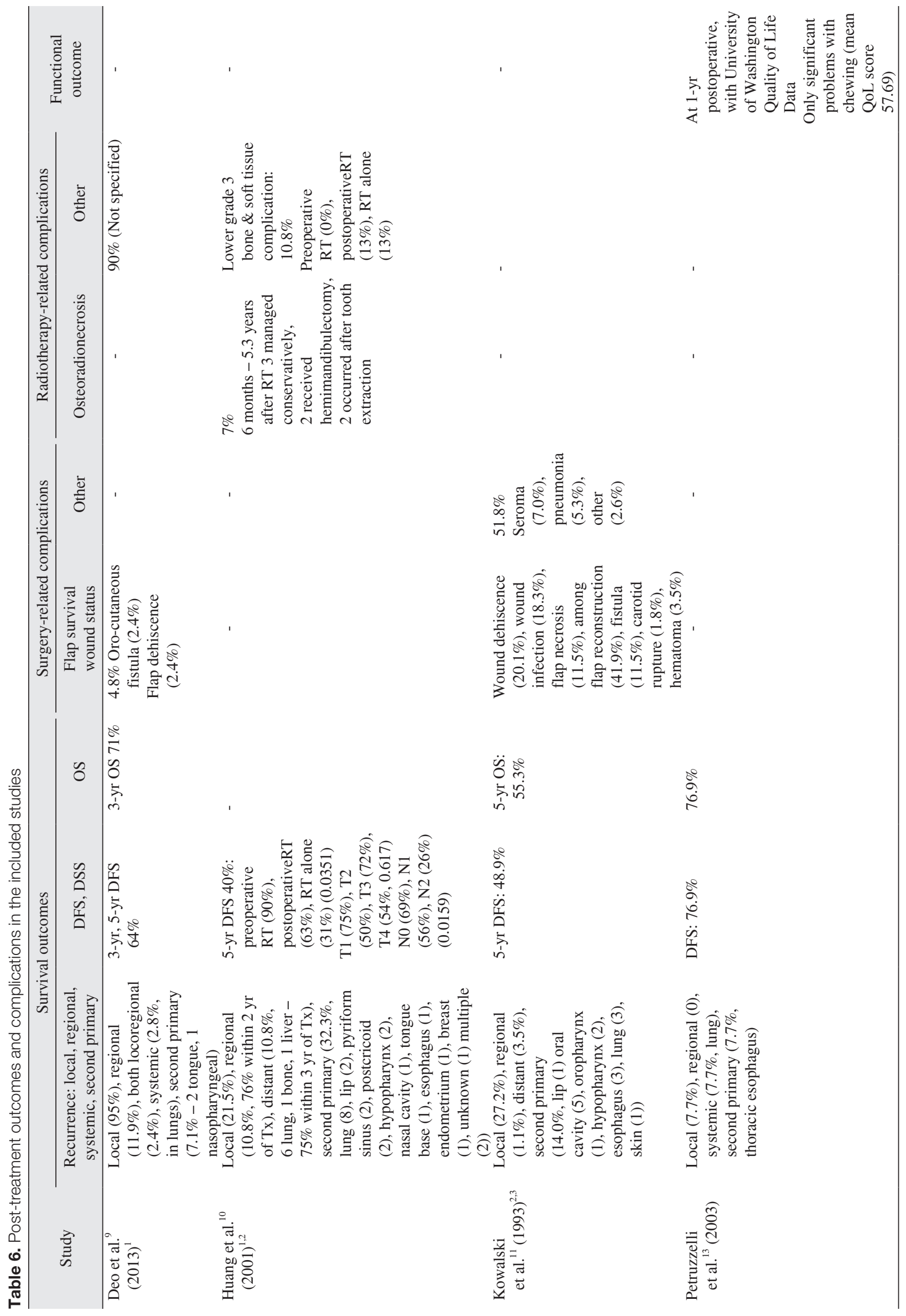




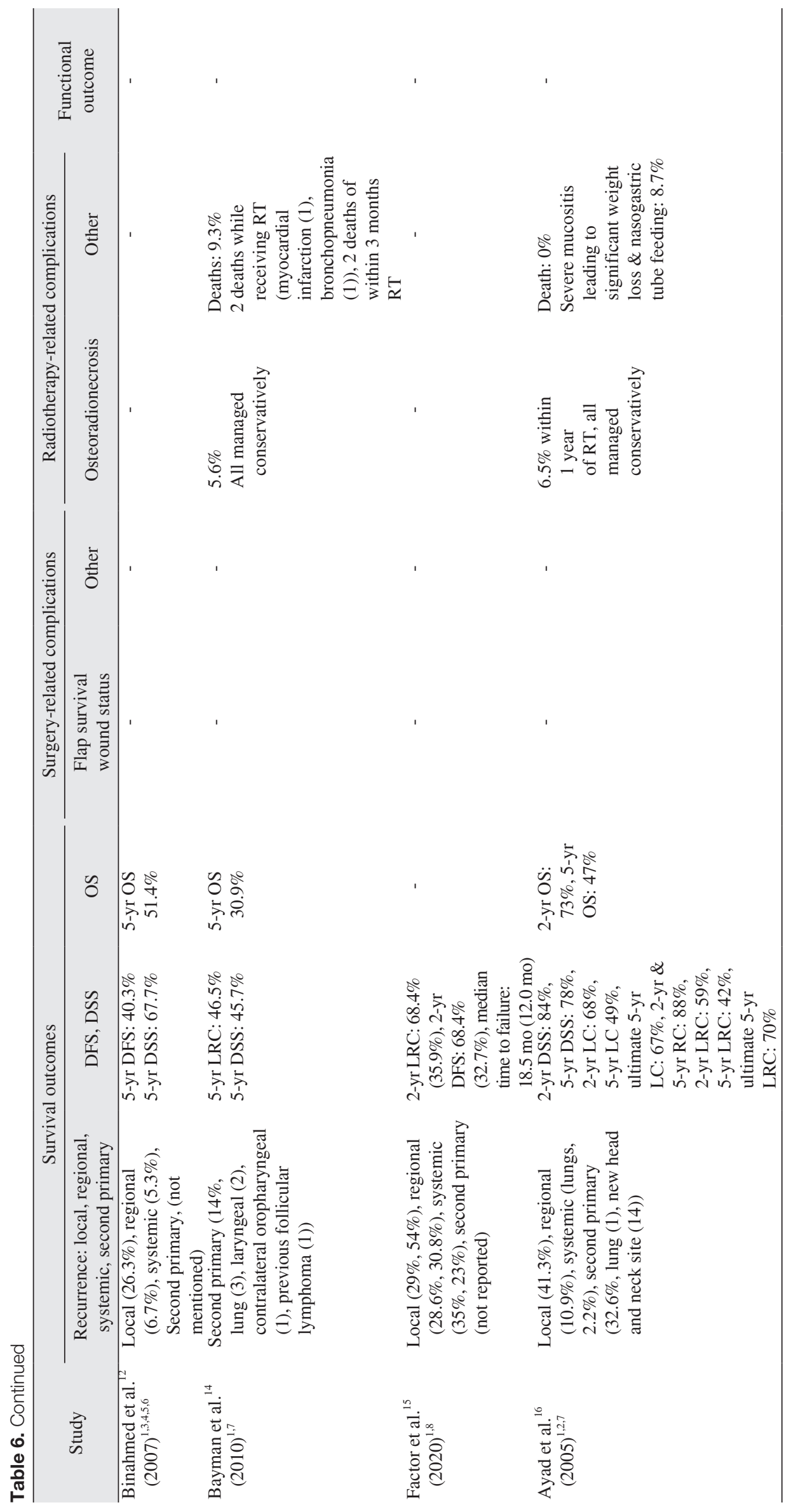




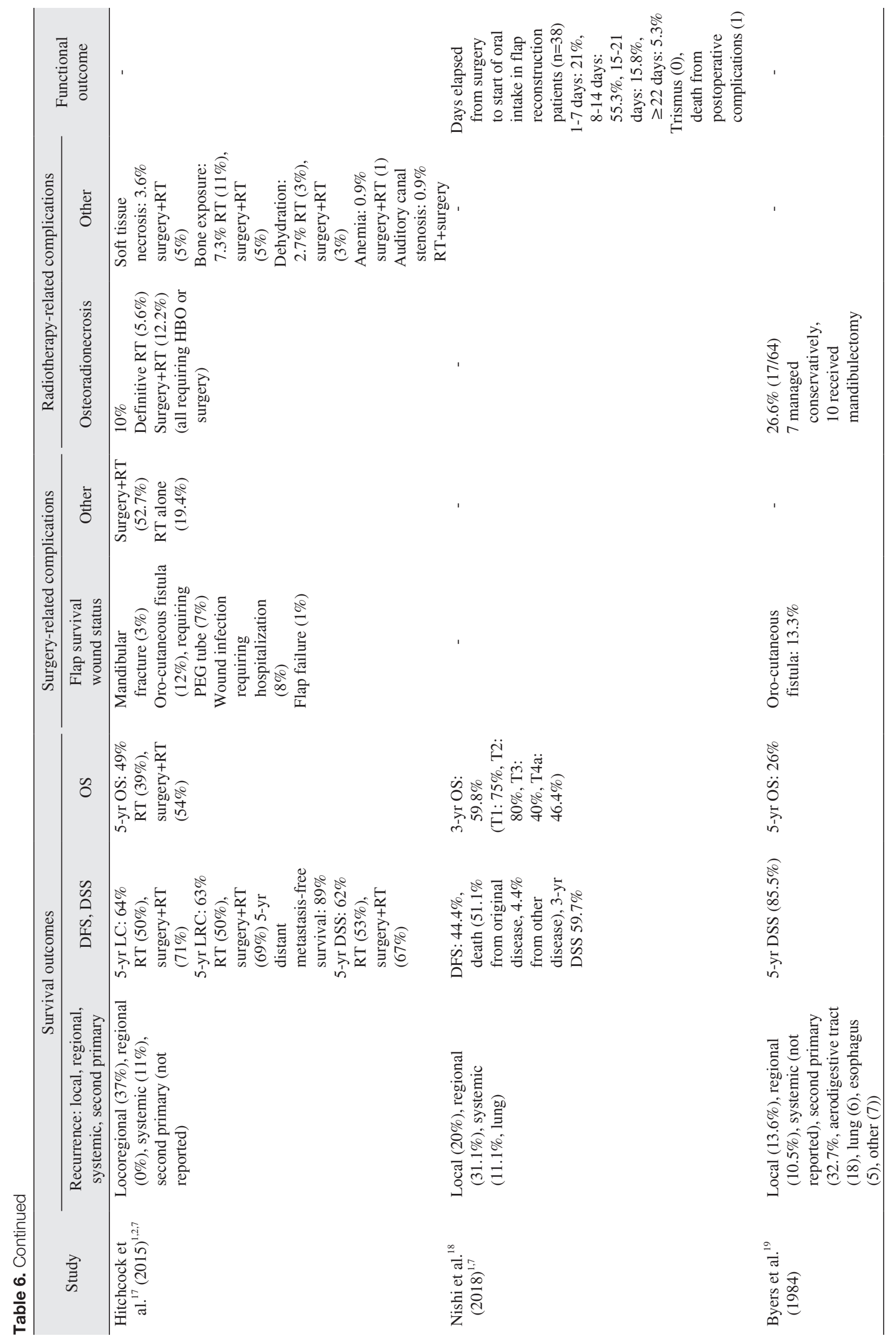




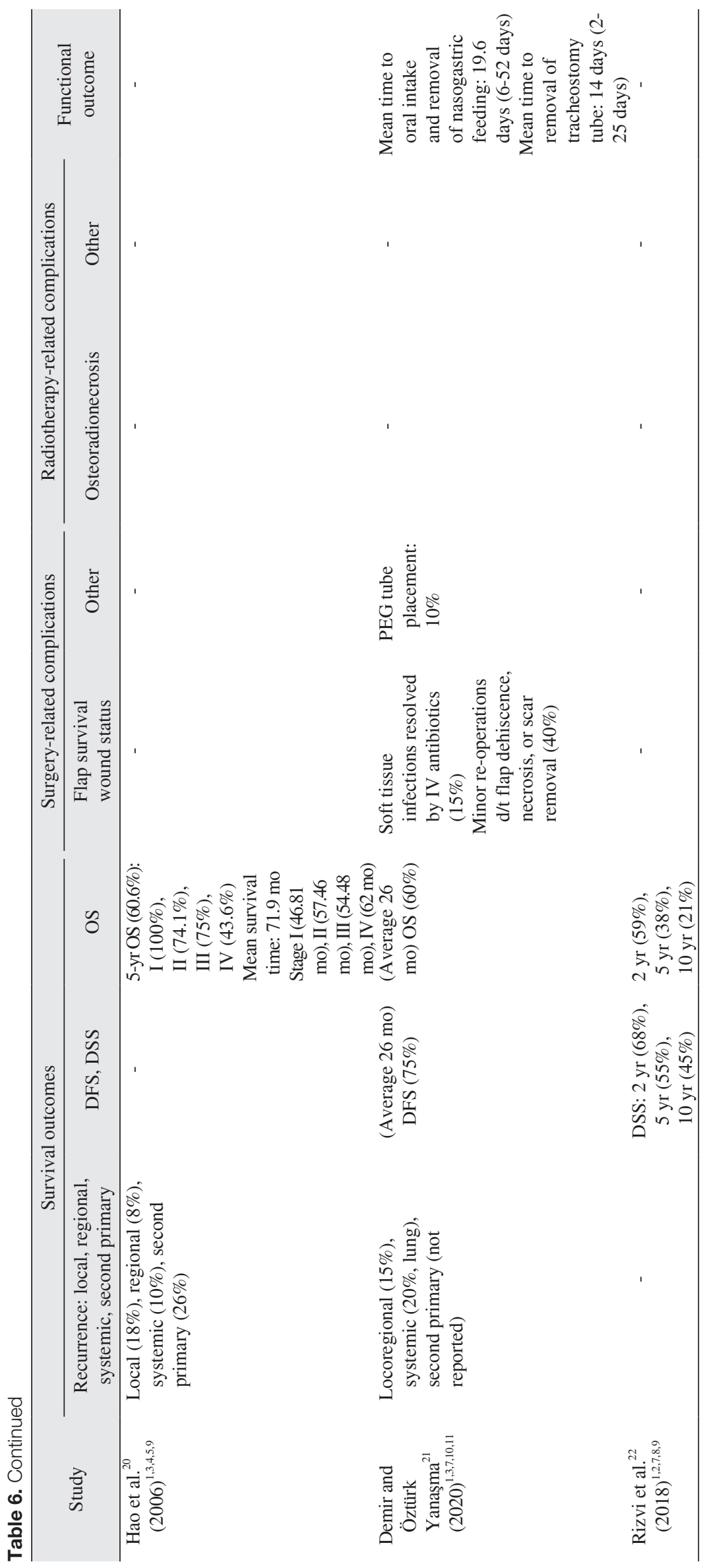




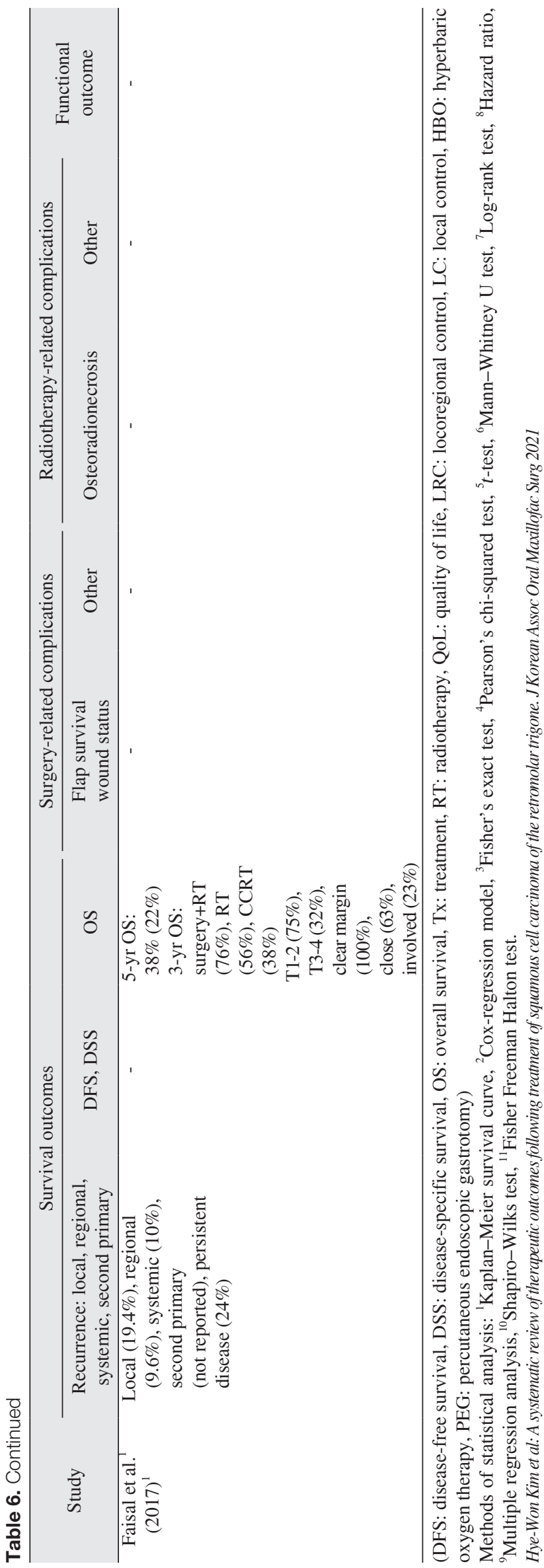

significantly decreased locoregional control ${ }^{17}$. Another study reported that poor prognostic factors for local control were the presence of bone invasion and a second primary lesion ${ }^{20}$. In one study, however, no significant prognostic factors for recurrence could be found ${ }^{15}$.

\section{Survival outcomes}

Disease-free survival was reported in eight studies ${ }^{9-13,15,18,21}$ and ranged from $40 \%{ }^{10}$ to $76.9 \%{ }^{13}$. (Table 6) Disease-specific survival was reported in seven other studies ${ }^{12,14,16-18,21,22}$. Among those studies, six investigated the presence of significant prognostic factors for disease-specific survival ${ }^{10,15-17,19,20}$. (Table 7) Five studies found that advanced nodal stage had a negative effect on disease-free survival ${ }^{9-11,16,22}$. Similar results were found for advanced tumor stage in two studies ${ }^{11,22}$ and inferior gingival involvement ${ }^{11,17}$ in two studies. However, contrary to those findings, Bayman et al. ${ }^{14}$ reported that tumor stage or nodal status did not influence the disease-specific or overall survival rates. Treatment modality was correlated with disease-free survival in three studies ${ }^{10,17,22}$. Rizvi et al. ${ }^{22}$ mentioned other significant prognostic factors such as age, race, and overall stage.

Among the 4,633 study subjects in the nine articles that discussed 5-year overall survival ${ }^{1,11,12,14,16,17,19,20,22}$, the total 5 -year overall survival rate was approximately $38.90 \%\left(26 \%{ }^{19}\right.$ to $60.6 \%{ }^{20}$ ). Only 3 -year overall survival rates of $71 \%{ }^{9}$ and $59.8 \%{ }^{18}$ were reported in two studies, and the evaluation period was not specified in two other articles ${ }^{13,21}$.(Tables 2, 6)

Nine studies identified prognostic factors that correlated with overall survival ${ }^{11,12,14,16-18,20-22}$. (Table 7) Nodal status was the most commonly reported prognostic factor, with five articles detecting its significant effect on overall survival ${ }^{11,18,20-22}$. Overall stage ${ }^{17,20,22}$, tumor stage $e^{11,22}$, treatment modality ${ }^{17,22}$, invasion to adjacent anatomic spaces ${ }^{11,20}$, margin status ${ }^{12}$, and age at diagnosis ${ }^{22}$ were also found to be significant factors affecting survival.

\section{Complications and functional outcomes}

Table 6 lists the rates of complications following surgery and radiotherapy documented in the analyzed articles. Of all the studies, only five investigated postoperative complications rates ${ }^{9,11,17,19,21}$, and six examined those related to radiotherapy $^{9,10,14,16,17,19}$. Oro-cutaneous fistula was the most prevalent postoperative complication, with its presence confirmed in $10.6 \%$ of the 395 subjects in the five studies, followed by 


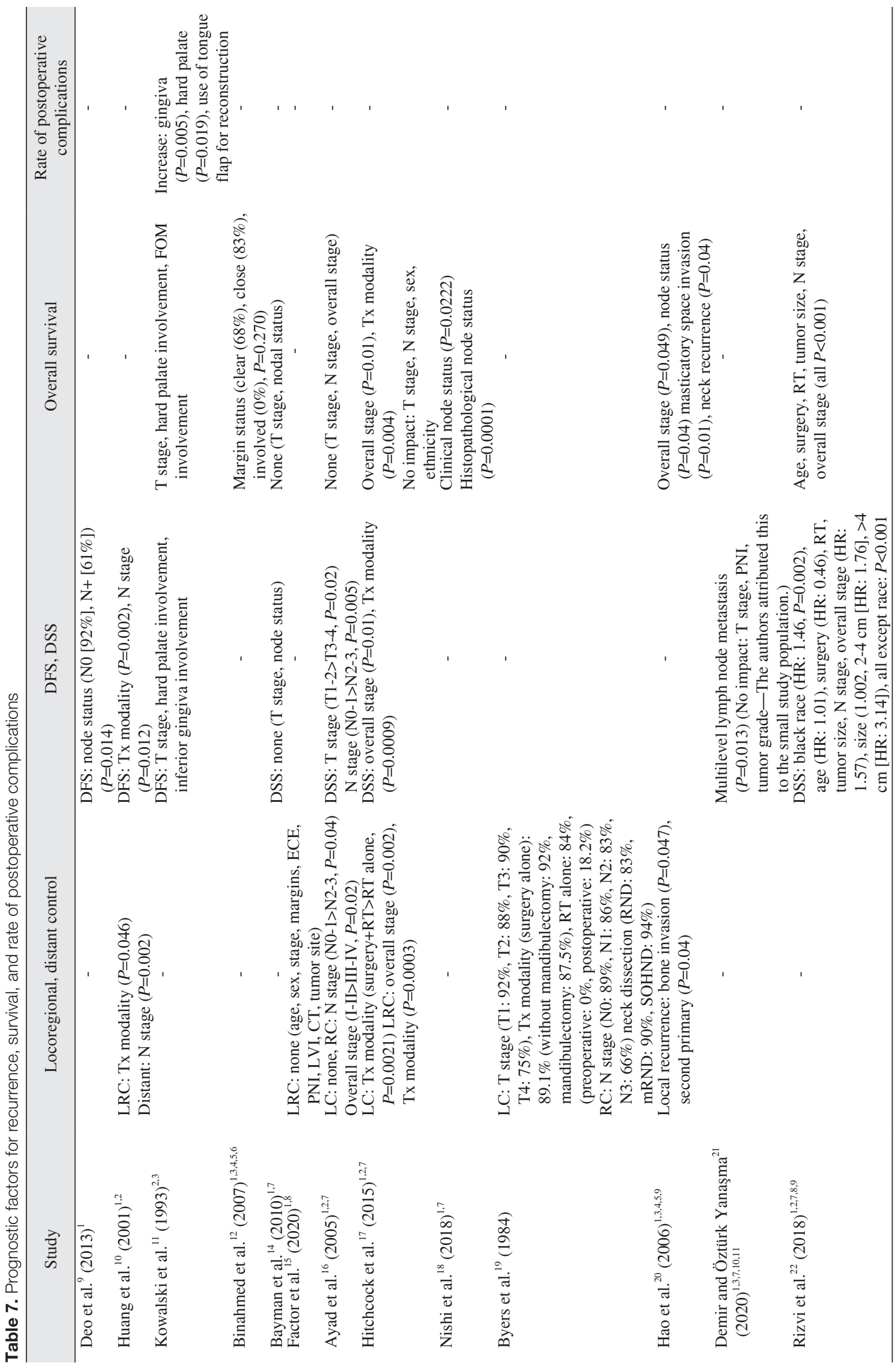




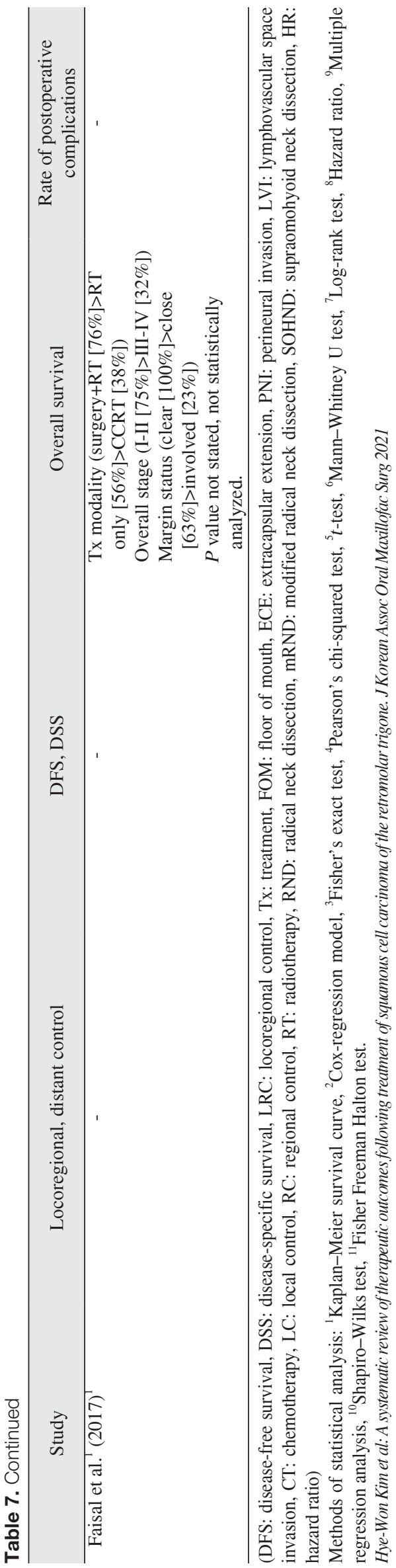

flap dehiscence $(8.1 \%)$, wound infection $(8.1 \%)$, flap necrosis $(5.6 \%)$, seroma formation $(3.5 \%)$, pneumonia $(3.5 \%)$, percutaneous endoscopic gastrotomy (PEG) tube placement $(2.5 \%)$, hematoma formation $(1.0 \%)$, mandibular fracture $(0.8 \%)$, and carotid rupture $(0.5 \%)$. (Table 2$)$ One study found that subjects with tumors that extended to the inferior gingiva or hard palate and those who underwent reconstruction via tongue flaps were more prone to postoperative complications than other patients ${ }^{11}$.(Table 7)

Among the 328 subjects who underwent radiotherapy in five studies ${ }^{10,14,16,17,19}$, osteoradionecrosis occurred in $11.6 \%$. The highest prevalence of $26.6 \%$ was reported by Byers et al. ${ }^{19}$ in 1984. More recent articles reported smaller rates of osteoradionecrosis, ranging from $5.6 \%{ }^{14}$ to $10 \%{ }^{17}$. Details about the other complications of radiotherapy documented in the reviewed studies are specified in Table 6.

Only three studies investigated functional outcomes following treatment ${ }^{13,18,21}$. The documented postoperative functional results are summarized in Table 6.

\section{Discussion}

RMT SCC generally carries a worse prognosis than neoplasms originating from other regions of the oral cavity because of its unique anatomic position and relatively late diagnosis $^{23}$. To the best of our knowledge, this is the first study to systematically review worldwide data for nearly 5,000 patients with RMT SCC and analyze their recurrence, survival, complications, functional outcomes, and relevant prognostic factors.

\section{Significant findings}

The articles retrieved for this review were all retrospective, and most of them originated from centers in North America. The patient-specific factor most commonly observed among those diagnosed with RMT SCC was smoking, followed by alcohol abuse. This is in accordance with findings from many other articles that have clearly established smoking and excessive alcohol consumption as risk factors for the development of oral $\mathrm{SCC}^{24-26}$.

A significant proportion of the reviewed subjects presented with advanced tumor stage, nodal metastasis, extranodal extension, and adjacent bone invasion. Similar results have also been reported in the previous literature. Many articles have demonstrated the strong correlation between the RMT site and advanced tumor stages ${ }^{27,28}$ and lymph node metastasis ${ }^{29}$ 
at the time of diagnosis. Because of its aggressive nature, one article recommended that neck dissection be performed for all cases of RMT SCC ${ }^{29}$.

It is also well known that the unique location of RMT SCCs in the posterior triangular-shaped area directly over the pterygomandibular raphe and their consequent proximity to the surrounding muscles, tonsillar pillar, maxillary tuberosity, and anterior ascending ramus of the mandible gives them a tendency to extend to other anatomic structures and erode bone, even in their early stages ${ }^{5}$. In this review, we also found that extension to several sublocations, especially the tonsillar pillar (36.3\%), soft palate (35.9\%), lower gum (32.7\%), and buccal mucosa $(20.8 \%)$, was reported in a significant number of subjects.

Mandibular invasion was pathologically confirmed in $24 \%$ of the 283 patients in six of the studies reviewed here. In 3.6\% to $15.4 \%$ of those patients, signs of bony invasion could not be detected in the preoperative computed tomography (CT) scans, but the invasion was confirmed through histopathological diagnosis ${ }^{9,13,19}$. This is in accordance with the findings of Lane et al. ${ }^{30}$, who reported that the sensitivity of CT for detecting underlying bone involvement in RMT SCC was only $50 \%$. They thus warned of the significant limitations that could exist in using negative CT scan results to determine the therapeutic approach for the overlying mandible. One limitation of the current systematic review is that most of the reviewed studies focused only on mandibular invasion; details about the maxillary infiltration rate were elaborated in only one study ${ }^{20}$. The authors of that article reported that in their series, the maxilla was more readily involved than the mandible. Because of the RMT's proximity to the maxillary tuberosity, pterygoid plate, and soft palate, paying attention to the maxilla is also imperative when treating RMT SCCs ${ }^{5,20}$. This highlights the need to consider tumor extension to the maxilla in future studies.

The management of patients with SCC varied considerably among studies; radical resection followed by adjunctive therapy, surgery alone, radiotherapy or chemotherapy without surgery, and neo-adjuvant therapy followed by salvage surgery were all used. Not surprisingly, many of the articles analyzed by this review reported that 5-year disease-specific survival and overall survival depended on the treatment approach, with primary surgery resulting in the highest survival rates ${ }^{1,10,17,19,22}$. Due to the high rate of lymph node metastasis, mandibular infiltration, and advanced stage at the time of diagnosis, aggressive surgery is often warranted for the definitive treatment of carcinomas of the RMT region ${ }^{5,27-29,31}$. In this study, aggressive mandibular surgery, such as hemi- mandibulectomy (39.6\%) and segmental mandibulectomy $(21.5 \%)$, was undertaken for more than $60 \%$ of the reviewed populations, and either radical neck dissection (RND) (44.1\%) or modified radical neck dissection (mRND) (23.6\%) was selected as the neck dissection method of choice for nearly $70 \%$ of patients. Free flap reconstruction was necessary in $49.5 \%$ of patients, which suggests the extensive nature of the resection and advanced tumor stage at the time of surgery. On the contrary, for $31.90 \%$ of the study subjects, primary

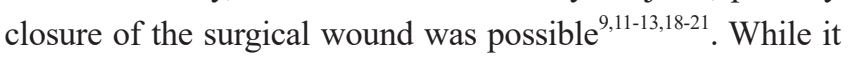
would be plausible to assume that most of those patients were diagnosed at early stages, neither the tumor nor overall prognostic stages for which primary closure or free flap surgery were performed were specified in any of the reviewed manuscripts. Therefore, future studies should further explore those associations and determine the precise role of reconstructive surgery in the treatment of early and advanced RMT SCCs.

In this review, despite the aggressive approach to the tumor via the lip-splitting method with or without mandibulectomy in $92 \%$ of the study population, high positive surgical margin rates of $33 \%{ }^{12}, 20 \%{ }^{15}$, and $57 \%{ }^{18}$ were reported. Many previous articles have demonstrated the significantly higher prevalence of positive margins in RMT tumors compared with those originating from other oral regions ${ }^{3,31-35}$. The limited surgical excision and exposure ${ }^{3,32-35}$ due to confinement from adjacent anatomic structures and the invasive nature of carcinomas arising in that location ${ }^{31}$ could explain that finding.

The total 5-year overall survival of the patients in this review was $38.9 \%$, which is significantly lower than the 5 -year survival rate of $66.2 \%$ among oral cavity cancers reported by the SEER database in $2016^{36}$. This low 5 -year survival rate can be partially attributed to the publication years, which date back to $1984^{19}$, and the inclusion of studies that included patients who underwent radiotherapy as the primary treatment $^{14,16}$. However, all but one study ${ }^{20}$ in the current review reported 5-year survival rates lower than $60 \%$, indicating the aggressive nature of tumors arising from this subsite.

The retrieved articles also reported relatively high rates of complications following surgery and radiotherapy. Complications associated with free flaps, such as the development of oro-cutaneous fistula, flap dehiscence, wound infection, and flap necrosis, were the most prevalent. Osteoradionecrosis following radiotherapy was also commonly reported. One previous retrospective review of 1,692 patients reported the RMT subsite to be an independent factor associated with osteoradionecrosis. In another systematic review, the retromolar region, along with the tongue and floor of the mouth, was reported to 
be one of the tumor sites with the highest risk of developing osteoradionecrosis (ORN) owing to its proximity to the mandible and consequent direct irradiation of the bone ${ }^{30}$. Similar findings have been reported in other previous studies ${ }^{37-39}$.

\section{Heterogeneity}

The aim of the current systematic review was to assess all the relevant data regarding the outcomes of RMT SCC, regardless of the individual tumor and treatment characteristics of the included subjects. Therefore, the studies included in this qualitative assessment displayed significant heterogeneity in terms of baseline tumor and treatment characteristics that could not be controlled. Those methodological and clinical differences might have biased the overall results of this study.

The number of subjects per study was widely distributed from $14^{15}$ to $4,022^{22}$. Approximately $83.1 \%$ of the total study population were patients in a single study ${ }^{22}$, and thus, it is arguable that our overall results might have been overly influenced by the results of that article, resulting in biased data. Conversely, the data from some studies ${ }^{13,15,21}$ might lack reliability and statistical power because they had study population of 20 or fewer people. Thus, post-treatment complication and mortality rates might have been under-reported.

Our review included studies from different publication years and study locations. Although more than half of the analyzed studies ${ }^{1,9,14,15,17,18,21,22}$ were published in the past 10 years, two studies were published more than 20 years ago. In contrast to the latter group of studies, which used only a combination of surgery and radiotherapy, most recent publications documented the use of chemotherapy ${ }^{1,14-18,20,21}$, which could have had a positive effect on survival and locoregional control. On the other hand, no significant differences were found in the general treatment patterns of American, Asian, and European hospitals.

Also of note is the heterogeneity in treatment modality and tumor traits of interest among the individual studies. The unfavorable survival outcomes, high rates of stage T3-4 patients, and aggressive surgery might partially be due to inclusion criteria demanding advanced stage tumors ${ }^{9}$ or the need for extended operations ${ }^{11}$. It is also plausible that the results regarding treatment modality and outcomes were influenced by the studies that investigated the outcomes of only subjects who underwent radiotherapy as the primary treatment ${ }^{14,17}$.

Our objective comparison of post-treatment survival rates between the included studies was also limited by their heterogeneous methodological traits. Although survival rates were reported in all the analyzed articles, only disease-free or disease-specific survival rates were reported in three ${ }^{10,13,15}$, and among those that did provide details regarding overall survival, only 2- or 3-year overall survival was reported in three ${ }^{9,18,21}$. Therefore, only the remaining nine articles could be included in the final analysis of 5-year overall survival.

\section{Other study limitations}

As a systematic review, this study has several limitations: the small number of analyzed articles, search boundaries, potential subjectivity in data selection, and poor quality of evidence in the overall data.

To enhance the reliability of the current review, we sought to minimize selection bias by applying stringent inclusion criteria for the articles, and as a result, only 15 studies were included in our analysis. The language inclusion criteria could also be a limitation because relevant data from studies published in languages other than English were not retrieved. We are aware that, despite cross-checking between independent reviewers via the DSR program, only data from the articles we selected were analyzed, so the possibility of selection bias exists.

Because SCCs originating from the RMT region are relatively uncommon and because the goal of our review was to investigate the overall outcomes of all RMT SCC patients regardless of the type of treatment, all the data analyzed came from retrospective, case-controlled studies. No randomized controlled trials or cohort studies have been conducted on this topic. Therefore, the overall level of evidence for the analyzed data was poor, and that might also have introduced selection biases. Moreover, the criteria for selecting the treatment modality were not clarified in most of the reviewed studies, which could also indicate biased data. These limitations highlight the need for randomized controlled trials or cohort studies with appropriate treatment selection and adequate methods for assessing outcomes.

Despite these shortcomings, this is the first retrospective review of extensive data on the outcomes of treatment for RMT SCC, and thus it will be a useful guideline for clinicians who need to select the treatment that will yield the best outcomes for their patients suffering from this rare but dangerous disease.

\section{Declaration of competing interests}

The authors declare that this research did not receive any specific grant from funding agencies in the public, commercial, or not-for-profit sectors. 


\section{ORCID}

Hye-Won Kim, https://orcid.org/0000-0002-5959-4080
Moon-Young Kim, https://orcid.org/0000-0001-9596-7481
Chul-Hwan Kim, https://orcid.org/0000-0002-5199-2420

\section{Authors' Contributions}

H.W.K. and M.Y.K. participated in data collection, performed the statistical analysis, and wrote C.H.K. participated in the study design and coordination and helped to draft the manuscript. All authors read and approved the final manuscript.

\section{Conflict of Interest}

No potential conflict of interest relevant to this article was reported.

\section{References}

1. Faisal M, Abbas T, Khaleeq U, Adeel M, Anwer AW, Hussain R, et al. Treatment outcomes of rare retromolar trigone squamous cell carcinoma using combined modalities. Cureus 2017;9:e1203. https://doi.org/10.7759/cureus. 1203

2. Farhood Z, Simpson M, Ward GM, Walker RJ, Osazuwa-Peters N. Does anatomic subsite influence oral cavity cancer mortality? A SEER database analysis. Laryngoscope 2019;129:1400-6. https:// doi.org/10.1002/lary.27490

3. Luryi AL, Chen MM, Mehra S, Roman SA, Sosa JA, Judson BL. Positive surgical margins in early stage oral cavity cancer: an analysis of 20,602 cases. Otolaryngol Head Neck Surg 2014;151:98490. https://doi.org/10.1177/0194599814551718

4. Sowder JC, Cannon RB, Buchmann LO, Hunt JP, Hitchcock Y, Lloyd S, et al. Treatment-related determinants of survival in earlystage (T1-2N0M0) oral cavity cancer: a population-based study. Head Neck 2017;39:876-80. https://doi.org/10.1002/hed.24679

5. Mukherji SK, Pillsbury HR, Castillo M. Imaging squamous cell carcinomas of the upper aerodigestive tract: what clinicians need to know. Radiology 1997;205:629-46. https://doi.org/10.1148/radiology.205.3.9393513

6. Richardson WS, Wilson MC, Nishikawa J, Hayward RS. The wellbuilt clinical question: a key to evidence-based decisions. ACP J Club 1995;123:A12-3.

7. Liberati A, Altman DG, Tetzlaff J, Mulrow C, Gøtzsche PC, Ioannidis JP, et al. The PRISMA statement for reporting systematic reviews and meta-analyses of studies that evaluate health care interventions: explanation and elaboration. J Clin Epidemiol 2009;62:e1-34. https://doi.org/10.1016/j.jclinepi.2009.06.006

8. Saltaji H, Major MP, Altalibi M, Youssef M, Flores-Mir C. Longterm skeletal stability after maxillary advancement with distraction osteogenesis in cleft lip and palate patients. Angle Orthod 2012;82:1115-22. https://doi.org/10.2319/011212-27.1

9. Deo SV, Shukla NK, Kallianpur AA, Mohanti BK, Thulkar SP. Aggressive multimodality management of locally advanced retromolar trigone tumors. Head Neck 2013;35:1269-73. https://doi. org/10.1002/hed.23113
10. Huang CJ, Chao KS, Tsai J, Simpson JR, Haughey B, Spector GJ, et al. Cancer of retromolar trigone: long-term radiation therapy outcome. Head Neck 2001;23:758-63. https://doi.org/10.1002/hed.1108

11. Kowalski LP, Hashimoto I, Magrin J. End results of 114 extended "commando" operations for retromolar trigone carcinoma. Am J Surg 1993;166:374-9. https://doi.org/10.1016/s0002-9610(05)80336-8

12. Binahmed A, Nason RW, Abdoh AA, Sándor GK. Population-based study of treatment outcomes in squamous cell carcinoma of the retromolar trigone. Oral Surg Oral Med Oral Pathol Oral Radiol Endod 2007;104:662-5. https://doi.org/10.1016/j.tripleo.2007.04.004

13. Petruzzelli GJ, Knight FK, Vandevender D, Clark JI, Emami B. Posterior marginal mandibulectomy in the management of cancer of the oral cavity and oropharynx. Otolaryngol Head Neck Surg 2003;129:713-9. https://doi.org/10.1016/s0194-5998(03)01387-1

14. Bayman NA, Sykes AJ, Bonington S, Blackburn T, Patel M, Swindell R, et al. Primary radiotherapy for carcinoma of the retromolar trigone: a useful alternative to surgery. Clin Oncol (R Coll Radiol) 2010;22:119-24. https://doi.org/10.1016/j.clon.2009.10.017

15. Factor O, Su W, Lazarev S, Miles B, Genden E, Sharma S, et al. Rapid in-field failures following adjuvant radiation for buccal squamous cell carcinoma. Laryngoscope 2020;130:413-7. https:// doi.org/10.1002/lary.27996

16. Ayad T, Gélinas M, Guertin L, Larochelle D, Del Vecchio P, Tabet JC, et al. Retromolar trigone carcinoma treated by primary radiation therapy: an alternative to the primary surgical approach. Arch Otolaryngol Head Neck Surg 2005;131:576-82. https://doi. org/10.1001/archotol.131.7.576

17. Hitchcock KE, Amdur RJ, Morris CG, Werning JW, Dziegielewski PT, Mendenhall WM. Retromolar trigone squamous cell carcinoma treated with radiotherapy alone or combined with surgery: a 10-year update. Am J Otolaryngol 2015;36:140-5. https://doi. org/10.1016/j.amjoto.2014.10.005

18. Nishi H, Shinozaki T, Tomioka T, Maruo T, Hayashi R. Squamous cell carcinoma of the retromolar trigone: treatment outcomes. Auris Nasus Larynx 2018;45:337-42. https://doi.org/10.1016/ j.anl.2017.05.011

19. Byers RM, Anderson B, Schwarz EA, Fields RS, Meoz R. Treatment of squamous carcinoma of the retromolar trigone. Am J Clin Oncol 1984;7:647-52. https://doi.org/10.1097/00000421198412000-00011

20. Hao SP, Tsang NM, Chang KP, Chen CK, Huang SS. Treatment of squamous cell carcinoma of the retromolar trigone. Laryngoscope 2006;116:916-20. https://doi.org/10.1097/01. mlg.0000214900.07495.39

21. Demir UL, Öztürk Yanaşma H. Treatment outcomes for primary retromolar trigone carcinoma: a single institution experience. Turk Arch Otorhinolaryngol 2020;58:87-92. https://doi.org/10.5152/tao.2020.5153

22. Rizvi ZH, Alonso JE, Kuan EC, St John MA. Treatment outcomes of patients with primary squamous cell carcinoma of the retromolar trigone. Laryngoscope 2018;128:2740-4. https://doi.org/10.1002/ lary. 27234

23. Mazziotti S, Pandolfo I, D'Angelo T, Mileto A, Visalli C, Racchiusa $\mathrm{S}$, et al. Diagnostic approach to retromolar trigone cancer by multiplanar computed tomography reconstructions. Can Assoc Radiol J 2014;65:335-44. https://doi.org/10.1016/j.carj.2014.04.001

24. Zygogianni AG, Kyrgias G, Karakitsos P, Psyrri A, Kouvaris J, Kelekis N, et al. Oral squamous cell cancer: early detection and the role of alcohol and smoking. Head Neck Oncol 2011;3:2. https:// doi.org/10.1186/1758-3284-3-2

25. Llewelyn J, Mitchell R. Smoking, alcohol and oral cancer in South East Scotland: a 10-year experience. Br J Oral Maxillofac Surg 1994;32:146-52. https://doi.org/10.1016/0266-4356(94)90098-1

26. Schmidt BL, Dierks EJ, Homer L, Potter B. Tobacco smoking history and presentation of oral squamous cell carcinoma. J Oral Maxillofac Surg 2004;62:1055-8. https://doi.org/10.1016/ j.joms.2004.03.010

27. Morelatto RA, Herrera MC, Fernández EN, Corball AG, López 
de Blanc SA. Diagnostic delay of oral squamous cell carcinoma in two diagnosis centers in Córdoba Argentina. J Oral Pathol Med 2007;36:405-8. https://doi.org/10.1111/j.1600-0714.2007.00547.x

28. Seoane-Romero JM, Vázquez-Mahía I, Seoane J, Varela-Centelles P, Tomás I, López-Cedrún JL. Factors related to late stage diagnosis of oral squamous cell carcinoma. Med Oral Patol Oral Cir Bucal 2012;17:e35-40. https://doi.org/10.4317/medoral.17399

29. Burusapat C, Jarungroongruangchai W, Charoenpitakchai M. Prognostic factors of cervical node status in head and neck squamous cell carcinoma. World J Surg Oncol 2015;13:51. https://doi. org/10.1186/s12957-015-0460-6

30. Lane AP, Buckmire RA, Mukherji SK, Pillsbury HC 3rd, Meredith $\mathrm{SD}$. Use of computed tomography in the assessment of mandibular invasion in carcinoma of the retromolar trigone. Otolaryngol Head Neck Surg 2000;122:673-7. https://doi.org/10.1067/ mhn.2000.104806

31. Cheng A, Cox D, Schmidt BL. Oral squamous cell carcinoma margin discrepancy after resection and pathologic processing. J Oral Maxillofac Surg 2008;66:523-9. https://doi.org/10.1016/ j.joms.2007.08.040

32. Ellis OG, David MC, Park DJ, Batstone MD. High-volume surgeons deliver larger surgical margins in oral cavity cancer. J Oral Maxillofac Surg 2016;74:1466-72. https://doi.org/10.1016/ j.joms.2016.01.026

33. Brinkman D, Callanan D, O'Shea R, Jawad H, Feeley L, Sheahan P. Impact of $3 \mathrm{~mm}$ margin on risk of recurrence and survival in oral cancer. Oral Oncol 2020;110:104883. https://doi.org/10.1016/ j.oraloncology.2020.104883

34. Chen TC, Wang CP, Ko JY, Yang TL, Lou PJ. The impact of pathologic close margin on the survival of patients with early stage oral squamous cell carcinoma. Oral Oncol 2012;48:623-8. https://doi. org/10.1016/j.oraloncology.2012.01.015
35. Sutton DN, Brown JS, Rogers SN, Vaughan ED, Woolgar JA. The prognostic implications of the surgical margin in oral squamous cell carcinoma. Int J Oral Maxillofac Surg 2003;32:30-4. https:// doi.org/10.1054/ijom.2002.0313

36. Howlader N, Noone AM, Krapcho M, Neyman N, Aminou R, Waldron W, et al. SEER Cancer Statistics Review, 1975-2008 [Internet]. Bethesda (MD): National Cancer Institute [cited 2020 Sep 9]. Available from: https://seer.cancer.gov/csr/1975_2008/

37. Dieleman FJ, Phan TTT, van den Hoogen FJA, Kaanders JHAM, Merkx MAW. The efficacy of hyperbaric oxygen therapy related to the clinical stage of osteoradionecrosis of the mandible. Int $\mathrm{J}$ Oral Maxillofac Surg 2017;46:428-33. https://doi.org/10.1016/ j.ijom.2016.12.004

38. Curi MM, Dib LL. Osteoradionecrosis of the jaws: a retrospective study of the background factors and treatment in 104 cases. $\mathrm{J}$ Oral Maxillofac Surg 1997;55:540-4; discussion 545-6. https://doi. org/10.1016/s0278-2391(97)90478-x

39. Nabil S, Samman N. Risk factors for osteoradionecrosis after head and neck radiation: a systematic review. Oral Surg Oral Med Oral Pathol Oral Radiol 2012;113:54-69. https://doi.org/10.1016/ j.tripleo.2011.07.042

How to cite this article: Kim HW, Kim MY, Kim CH. A systematic review of therapeutic outcomes following treatment of squamous cell carcinoma of the retromolar trigone. J Korean Assoc Oral Maxillofac Surg 2021;47:291-314. https://doi.org/10.5125/ jkaoms.2021.47.4.291 